\title{
Article \\ Protein Sumoylation Is Crucial for Phagocytosis in Entamoeba histolytica Trophozoites
}

\author{
Mitzi Díaz-Hernández ${ }^{1,+}{ }^{\dagger}$, Rosario Javier-Reyna ${ }^{1,+}{ }^{\dagger}$ Izaid Sotto-Ortega ${ }^{2}$, Guillermina García-Rivera ${ }^{1}$, \\ Sarita Montaño ${ }^{3}{ }^{(\mathbb{C}}$, Abigail Betanzos ${ }^{1,4}{ }^{\mathbb{D}}$, Dxinegueela Zanatta ${ }^{1}$ and Esther Orozco ${ }^{1, *}$
}

1 Departamento de Infectómica y Patogénesis Molecular, Centro de Investigación y de Estudios Avanzados del IPN, Mexico City 07360, Mexico; mcdiaz@cinvestav.mx (M.D.-H.); rjavier@cinvestav.mx (R.J.-R.); gugarcia@cinvestav.mx (G.G.-R.); abetanzos@cinvestav.mx (A.B.); dxinegueela.zanatta@cinvestav.mx (D.Z.)

2 Bacteriología y Laboratorio Clínico, Universidad de Santander, 200004 Valledupar, Colombia; izmcrap@hotmail.com

3 Laboratorio de Bioinformática y Simulación Molecular, Facultad de Ciencias Químico Biológicas, Universidad Autónoma de Sinaloa, Sinaloa 80030, Mexico; mmontano@uas.edu.mx

4 Consejo Nacional de Ciencia y Tecnología (Conacyt), Mexico City 03940, Mexico

* Correspondence: esther@cinvestav.mx; Tel.: +52-55-5747-5642

+ These authors contributed equally to this work.

check for updates

Citation: Díaz-Hernández, M.; Javier-Reyna, R.; Sotto-Ortega, I.; García-Rivera, G.; Montaño, S.; Betanzos, A.; Zanatta, D.; Orozco, E. Protein Sumoylation Is Crucial for Phagocytosis in Entamoeba histolytica Trophozoites. Int. J. Mol. Sci. 2021, 22, 5709. https://doi.org/10.3390/ ijms22115709

Academic Editor: Irmgard Tegeder

Received: 26 March 2021

Accepted: 6 May 2021

Published: 27 May 2021

Publisher's Note: MDPI stays neutral with regard to jurisdictional claims in published maps and institutional affiliations.

Copyright: (c) 2021 by the authors. Licensee MDPI, Basel, Switzerland. This article is an open access article distributed under the terms and conditions of the Creative Commons Attribution (CC BY) license (https:// creativecommons.org/licenses/by/ $4.0 /)$.
Abstract: Posttranslational modifications provide Entamoeba histolytica proteins the timing and signaling to intervene during different processes, such as phagocytosis. However, SUMOylation has not been studied in E. histolytica yet. Here, we characterized the E. histolytica SUMO gene, its product (EhSUMO), and the relevance of SUMOylation in phagocytosis. Our results indicated that EhSUMO has an extended $\mathrm{N}$-terminus that differentiates SUMO from ubiquitin. It also presents the GG residues at the C-terminus and the $\Psi$ KXE/D binding motif, both involved in target protein contact. Additionally, the E. histolytica genome possesses the enzymes belonging to the SUMOylation-deSUMOylation machinery. Confocal microscopy assays disclosed a remarkable EhSUMO membrane activity with convoluted and changing structures in trophozoites during erythrophagocytosis. SUMOylated proteins appeared in pseudopodia, phagocytic channels, and around the adhered and ingested erythrocytes. Docking analysis predicted interaction of EhSUMO with EhADH (an ALIX family protein), and immunoprecipitation and immunofluorescence assays revealed that the association increased during phagocytosis; whereas the EhVps32 (a protein of the ESCRT-III complex)-EhSUMO interaction appeared stronger since basal conditions. In EhSUMO knocked-down trophozoites, the bizarre membranous structures disappeared, and EhSUMO interaction with EhADH and EhVps32 diminished. Our results evidenced the presence of a SUMO gene in E. histolytica and the SUMOylation relevance during phagocytosis. This is supported by bioinformatics screening of many other proteins of E. histolytica involved in phagocytosis, which present putative SUMOylation sites and the YKXE/D binding motif.

Keywords: SUMOylation; phagocytosis; E. histolytica; ESCRT machinery; EhADH adhesin

\section{Introduction}

As in other eukaryotes, in Entamoeba histolytica, the protozoan causative of human amoebiasis, cellular activities, including the attack to the target cell, are widely controlled by posttranslational modifications (PTMs) of proteins. Together with the perpetual movement of trophozoites, virulence expression requires intensive vesicular traffic and association to and disassociation from proteins performing the concatenated events that conduct target molecules through several compartments, for recycling or digestion. PTMs range from peptide bond cleavage and addition of phosphate and other small chemical groups, carbohydrates, and lipids to the alteration of proteins by the conjugation of modifiers such as ubiquitin and SUMO. The knowledge of the changes suffered by molecules involved in 
adherence to and invasion and phagocytosis of trophozoites to the target cells are pivotal to get a more comprehensive view of the parasite virulence mechanisms.

SUMO is a 10 to $13 \mathrm{kDa}$ small ubiquitin-related modifier that shares $18 \%$ similarity with ubiquitin in its three-dimensional structure [1]. In the N-terminus, SUMO has an extended 10 to 25 amino acid chain, absent in ubiquitin. As this later, SUMO conjugates to its target by an isopeptide bond formed on a lysin present in the consensus sequence

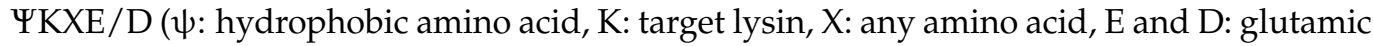
and aspartic acids, respectively) [2]. However, many other reports indicate that alternative sequences can be used for SUMO binding [3-5]. Furthermore, SUMO can associate to target proteins as a single moiety or as SUMO polymers [6] in an ATP-dependent event that requires the action of E1, E2, and E3 enzymes. DeSUMOylation, the reverse process, occurs by the specific proteases UIp1a and UIp1b [7].

SUMOylation-deSUMOylation is a switch to control the cellular location of proteins and their interaction with other molecules [8]. Cell growth, differentiation, response to stress, regulation of signal transduction, gene expression, and chromatin remodeling, among others, require SUMOylation of certain proteins $[9,10]$. In protozoan parasites, it is known that SUMOylation takes part in cell-cycle progression and influences morphology in Giardia lamblia [11], while in Trypanosoma brucei, it contributes to chromatin organization [12] and in Plasmodium falciparum, participates in invasion [13].

ESCRT machinery is deeply involved in the phagocytosis of E. histolytica trophozoites [14-16]. EhVps2, EhVps20, EhVps24, and EhVps32, members of ESCRT-III complex, and EhADH, an ALIX family protein [15] and accessory member of the ESCRT machinery, participate in membrane deformation, necessary for pseudopodia and vesicle generation [17]. They are also part of the scission apparatus to form intraluminal vesicles (ILVs) in multivesicular bodies (MVBs) [17]. SUMOylation could be one of the signals for the time and place of the ESCRT proteins to act during ingestion and prsocessing of the prey, but SUMO has not been characterized in E. histolytica. Besides the advancement in the comprehension of the molecular events occurring during phagocytosis, the importance of understanding these phenomena relies on the possibility of carrying out the blockage of specific parasite molecules and develop better diagnostic and therapeutic methods against E. histolytica that infects 50 million people and kills 100,000 annually, around the world [18]. We pursued here the identification and characterization of SUMO in this parasite and investigated whether ESCRT proteins are SUMOylated during phagocytosis. Particularly, we explored the association of SUMO with EhADH and EhVps32 proteins to scrutinize the changes that they undergo, during this event. The results evidenced the active participation of SUMOylation in phagocytosis.

\section{Results}

2.1. In Silico Analysis Predicts the Existence of SUMO and the Sumoylation-Desumoylation Machineries in E. histolytica

To investigate whether the proteins involved in phagocytosis go through SUMOylation, we first performed bioinformatics analysis to search for SUMO genes in the AmoebaDB (http:/ / amoebadb.org/amoeba/accessed on 29 April 2021), using as a template the SUMO sequence from G. lamblia [11,19]. Our search revealed two candidates in E. histolytica: EHI_170060 and EHI_151620. However, EHI_151620 predicts a product without the glycine residues (GG) at the C-terminus, a characteristic of SUMO [20]. In contrast, the EHI_170060 open reading frame is a $345 \mathrm{bp}$ intronless sequence with $33 \%$ identity to the G. lamblia SUMO gene. It is located at the complementary DNA strand, between the fragments annotated as EH_170050 and EH_170070, at the 46,961 and 47,530 bp (Figure 1A). By its sequence, we estimated a protein of $12.6 \mathrm{kDa}$ (EhSUMO) that has the extra amino acids at the amino terminus, recognized as the principal difference between SUMO and ubiquitin [21,22]. It has two $\Psi \mathrm{KXE} / \mathrm{D}$ consensus motifs at 21 to 24 and 30 to 34 residues, and displays the GG doublet at the C-terminus (112 and 113 residues), both described as SUMO interaction sites for target proteins [20] (Figure 1B). E. histolytica, as other protozoa [11], 
and Saccharomyces cerevisiae [23], Drosophila melanogaster [24], and Caenorhabditis elegans [25], has only one intronless SUMO gene, while vertebrates have four [3], and plants, eight [26].

A

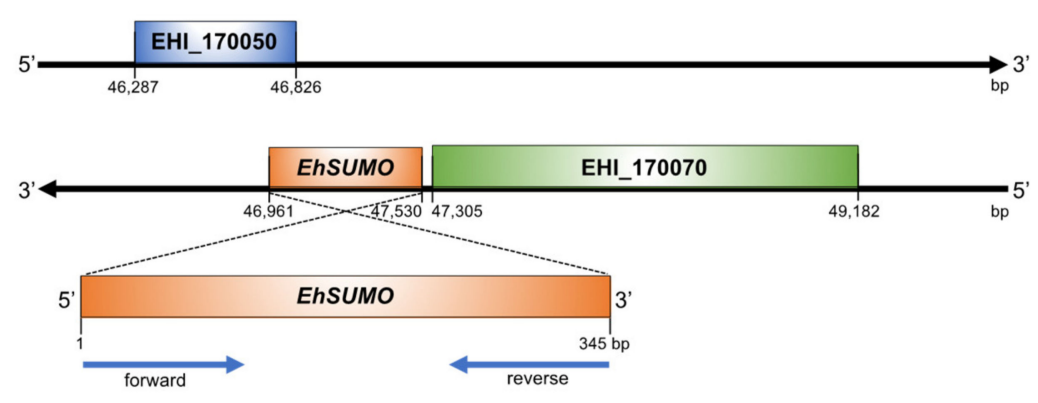

C

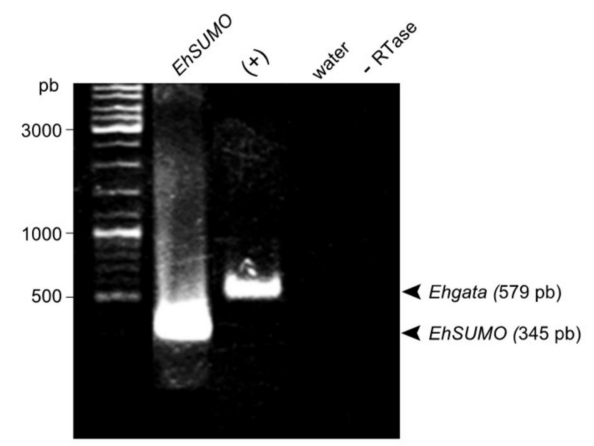

B

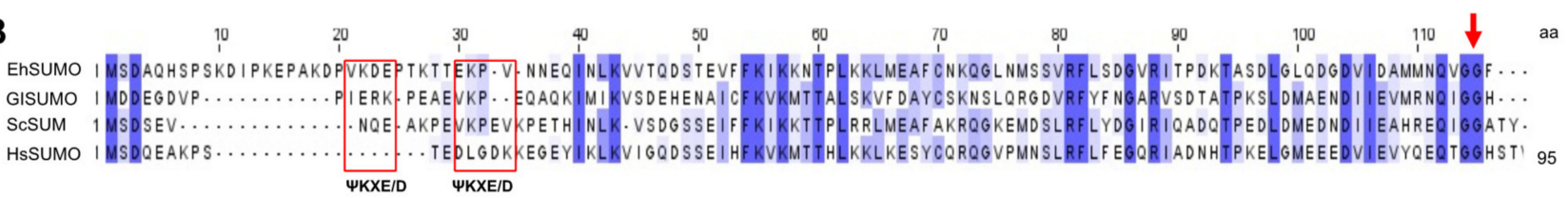

Figure 1. Identification and location of the EhSUMO gene in E. histolytica genome. (A) Location of EhSUMO gene in the genome. EhSUMO is in a contig located between 47,530 to 46,961 bp in the DNA negative chain flanked by two hypothetic genes (EHI_170050 and EHI_170070). Blue arrows: primer designed for EhSUMO amplification. (B) Comparative alignment of predicted EhSUMO amino acid sequence with proteins from other organisms, the blue color indicates the identity and similarity of amino acids. Red squares signal the $\Psi$ KXE/D motifs and arrow the GG doublet. (C) PCR amplification using complementary DNA (cDNA) as a template and specific primers for EhSUMO. Ehgata: positive control (+). Negative controls: in the mixture instead of template water was added or in the cDNA production, the RTase was omitted (-RTase). Arrowheads: PCR products.

Multiple alignments of EhSUMO amino acid sequence with SUMO of $S$. cerevisiae, $H$. sapiens, and G. lamblia, revealed 55, 48, and 33\% identity, respectively (Figure 1B), and the whole gene sequence confirmed the presence of the additional bases at the amino terminus and the GG motif at the C-terminus (Figure 1B,C).

The interactome, carried out with the putative EhSUMO as a bait and the STRING database (http:/ / sumosp.biocuckoo.org accessed on 29 April 2021), predicted E. histolytica proteins that interact with SUMO to perform different functions (Table 1), already described in other systems. We identified the putative E. histolytica genes and proteins required for SUMOylation, to compare them with those of other organisms [7]. E1 (EHI_035540), E2a (EH1_178500), E2b (EHI_14747), E3a (EHI_0988320), and E3b (EHI_069470), presumptive SUMOylation enzymes, revealed identities from 29 to $56 \%$ to S. cerevisiae, 27.8 to $53.5 \%$ to H. sapiens SUMO-2 gene, and 25 to $49 \%$ to G. lamblia (Table 2).

Table 1. In silico interactions of EhSUMO with other E. histolytica putative proteins related to the SUMO machinery.

\begin{tabular}{cc}
\hline Putative Protein & Access Number \\
Ran GTPase-activating protein & EHI_185290 \\
SP-RING zinc finger domain-containing protein & EHI_069470 \\
SP-RING zinc finger domain-containing protein & EHI_152530 \\
Ubiquitin-conjugating enzyme family protein & EHI_147470 \\
Ubiquitin-conjugating enzyme family protein ubiquitin-conjugating enzyme E2 & EHI_178500 \\
Ulp1 protease family, C-terminal catalytic domain containing & EHI_067510 \\
Ubiquitin-activating enzyme ubiquitin-like 1-activating enzyme E1 B & EHI_035540 \\
Ulp1 protease family, c-terminal catalytic domain containing & EHI_097940 \\
Proliferating cell nuclear antigen (PCNA) & EHI_128450 \\
\hline
\end{tabular}


Table 2. Comparison of putative proteins involved in SUMOylation in E. histolytica, S. cerevisiae, H. sapiens, and G. lamblia.

\begin{tabular}{|c|c|c|c|c|c|c|c|c|}
\hline Protein & E. histolytica & S. cerevisiae & Identity & H. sapiens & Identity & G. lamblia & Identity & Protein Type \\
\hline SUMO & EHI_170060 & YDR510W & $55 \%$ & NP_008868.3 & $48.35 \%$ & GL50803_7760 & $33 \%$ & $\begin{array}{l}\text { SUMO protein } \\
\text { ubiquitin-activating enzyme, } \\
\text { putative }\end{array}$ \\
\hline E1 & EHI_035540 & YDR390C & $35 \%$ & NP_005490.1 & $36 \%$ & GL50803_6288 & $25 \%$ & $\begin{array}{l}\text { SUMO-conjugating enzyme } \\
\text { UBC9, putative }\end{array}$ \\
\hline E2a & EHI_178500 & YDL064W & $51 \%$ & NP_003336.1 & $49.67 \%$ & GL50803_24068 & $46 \%$ & $\begin{array}{l}\text { SUMO-conjugating enzyme } \\
\text { UBC } 9 \text {, putative }\end{array}$ \\
\hline $\mathrm{E} 2 \mathrm{~b}$ & EHI_147470 & YDL064W & $56 \%$ & NP_003336.1 & $53.55 \%$ & GL50803_24068 & $49 \%$ & sumo ligase, putative \\
\hline E3a & EHI_098320 & YOR156C & $29 \%$ & NP_775298.1 & $27.88 \%$ & GL50803_11930 & $38 \%$ & sumo ligase, putative \\
\hline E3b & EHI_069470 & YOR156C & $31 \%$ & XP_011538282.1 & $32.22 \%$ & GL50803_11930 & $40 \%$ & sumo ligase, putative \\
\hline * Uplla & EHI_067510 & YPL020C & $27 \%$ & XP_006719425.1 & $27.5 \%$ & GL50803_16438 & $25 \%$ & $\begin{array}{l}\text { sentrin/sumo-specific } \\
\text { protease, putative }\end{array}$ \\
\hline${ }^{*}$ Upl1b & EHI_097940 & YIL031W & $24 \%$ & NP_001070671.1 & $23.6 \%$ & GL50803_16438 & $32 \%$ & $\begin{array}{l}\text { Ulp1 protease family, } \\
\text { C-terminal catalytic } \\
\text { domain-containing protein }\end{array}$ \\
\hline
\end{tabular}

Putative proteins in charge of deSUMOylation: UIp1a (EHI_067510), and UIp1b (EHI_097940) exhibited 23.6 to $44.3 \%$ identities to their orthologues (Table 1). The phylogenetic tree obtained using the MEGAT7 software showed that EhSUMO is close to D. discoideum, T. cruzi, and Toxoplasma gondii SUMO proteins, whereas it has a more distant phylogenetic relationship with the H. sapiens orthologues (Figure 2). The bioinformatics analysis strongly suggests that E. histolytica has a SUMO gene and those involved in the SUMOylation and deSUMOylation machinery.

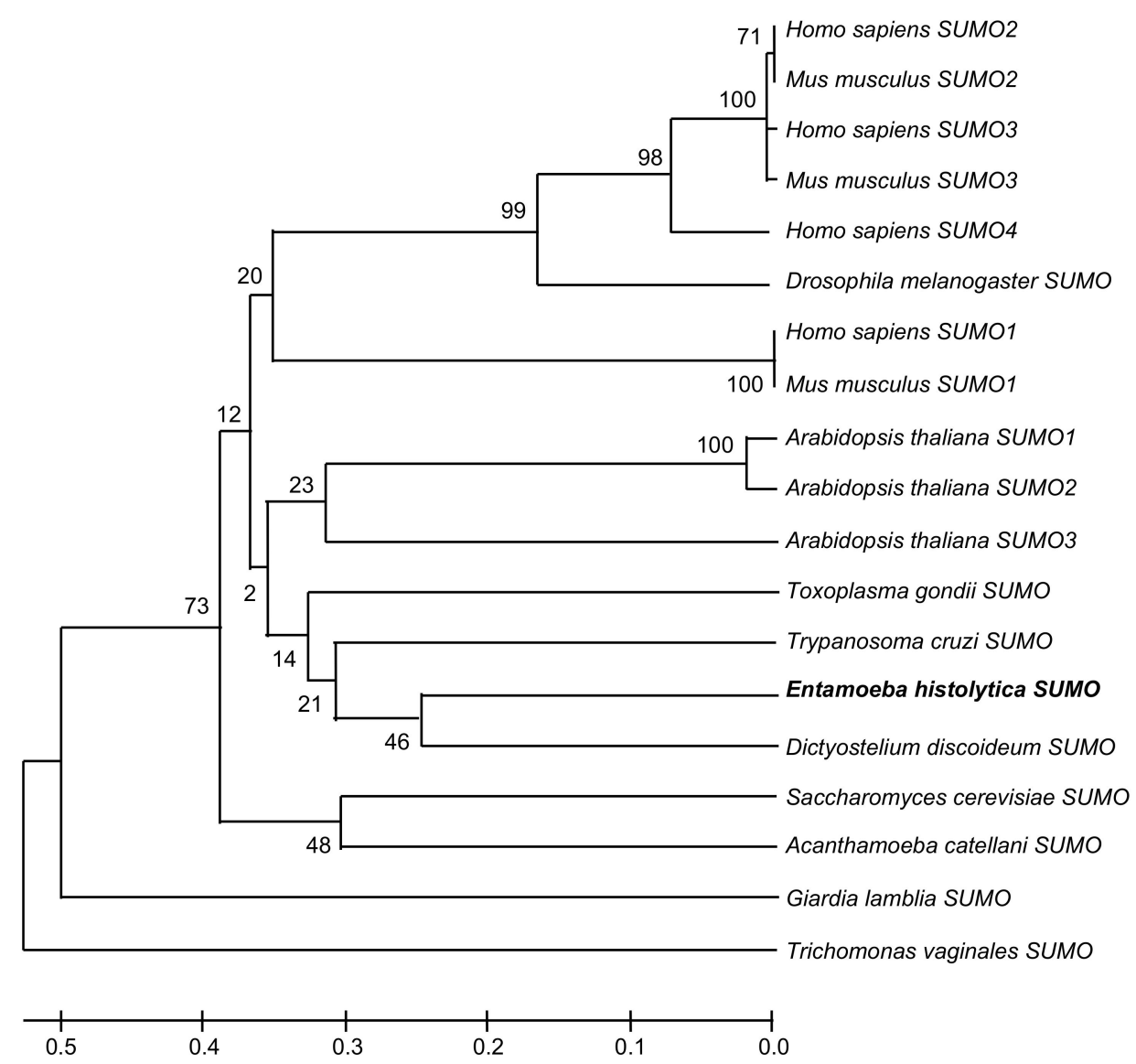

Figure 2. Phylogenetic analysis of EhSUMO. Phylogenetic tree performed by UPGMA, using MEGA 5.05 software, shows the position of E. histolytica SUMO protein among different species. Numbers in horizontal lines indicate the confidence percentages of the tree topology from bootstrap analysis of 1000 replicates. 


\subsection{The Predicted 3D-Structure of EhSUMO Is Like Other Orthologues}

To confirm that the sequence that we were working with is a bona fide SUMO protein, we obtained its secondary and tertiary structures. The secondary structure showed the 69 amino acid chain forming the ubiquitin-2Rad60SUMO like-domain (Figure 3A), with a similar size to the one of G. lamblia and close to other orthologous $[11,19,27-29]$. The EhSUMO three-dimensional (3D) model, formed by a single $\alpha$-helix and four $\beta$-strands, overlapped with the ones predicted for G. lamblia (RMSD: 0.53), and S. cerevisiae (RMSD: 1.26) (PDB:1L2NB), and H. sapiens (RMSD:1.20) SUMO-2 (PDB:1A5R) protein crystals [1,30] (Figure 3B). These findings strengthen the assumption that the EHI_170060 contig corresponds to the phylogenetically conserved SUMO in E. histolytica.

A
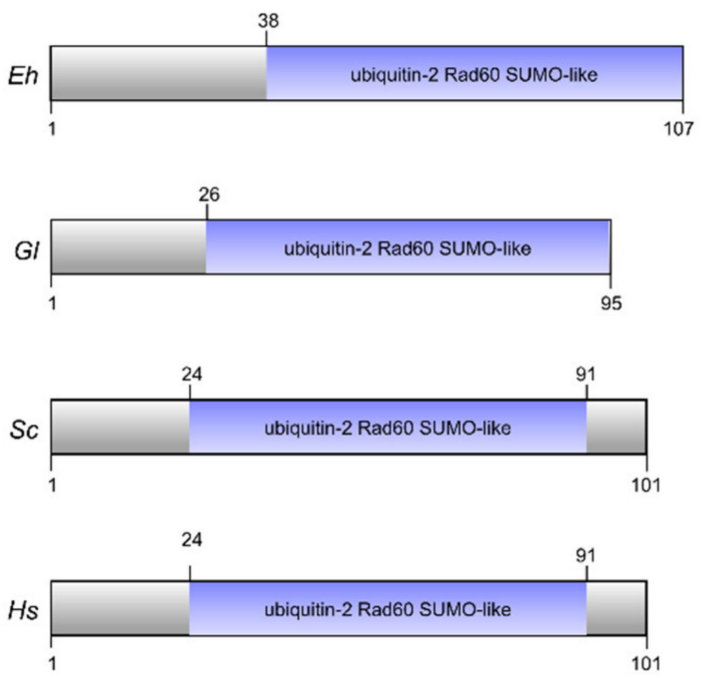

B

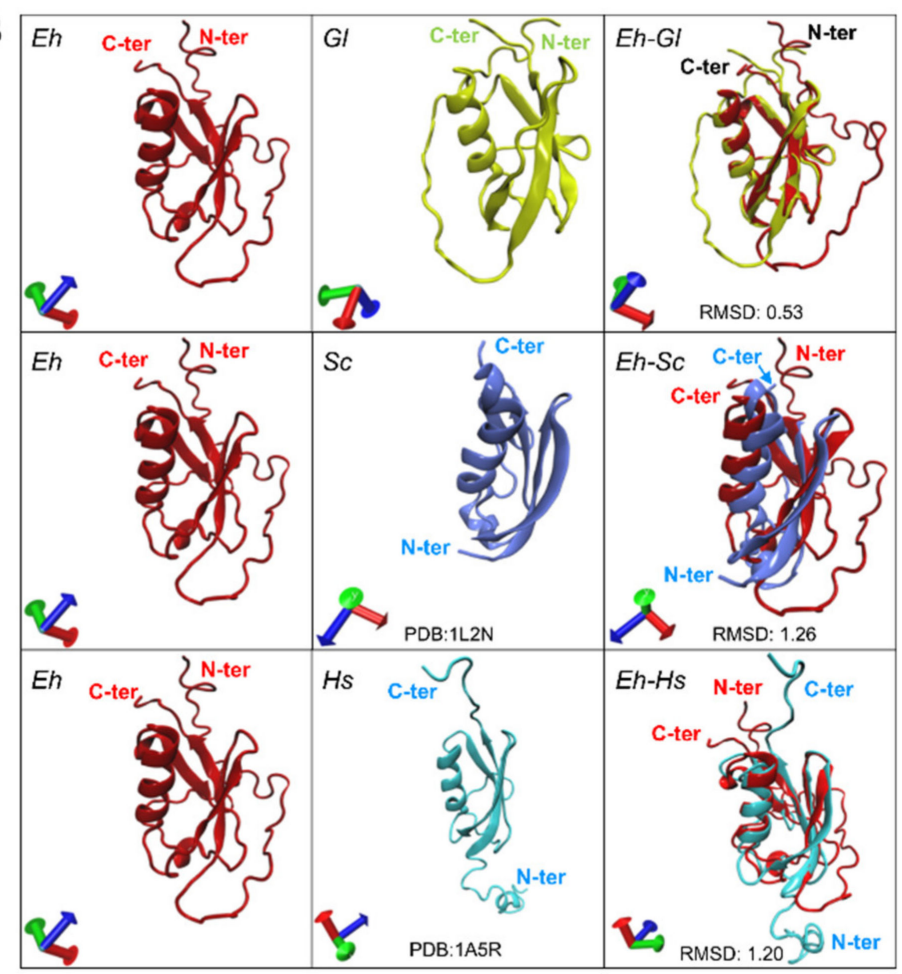

Figure 3. Secondary and tertiary structures of EhSUMO and its orthologous. (A) Schematic comparison of functional domains of EhSUMO and other SUMO proteins from different systems. Numbers at the right correspond to the amino acids forming each protein. (B) 3D-model of EhSUMO protein (Eh), overlapped with those of G. lamblia (Gl), S. cerevisiae (Sc), and $H$. sapiens $(H s)$. The $\mathrm{N}$ - and $\mathrm{C}$-terminus regions are signaled in red letters. At the bottom of each square are indicated the predicted 3D structures used for G. lamblia and H. sapiens.

The EhSUMO 3D model was obtained from the I-TASSER server, selected according to its C-score and the best Ramachandran plot values (Figure 4A). After $200 \mathrm{~ns}$ of molecular dynamic simulations (MDS) in a soluble environment by the NAMD software, the EhSUMO 3D model conserved a single $\alpha$-helix and four $\beta$-strands; the rest of the residues appeared lightly twisted in random soft coil and linear structures. The Ramachandran plot showed $98.2 \%, 75.7 \%$, and $1.83 \%$ amino acids in the favored, allowed, and outside the allowed regions, respectively. Residues distribution indicated that torsion angles of certain amino acids were refined in comparison with those obtained before MDS (Figure 4A). 
A

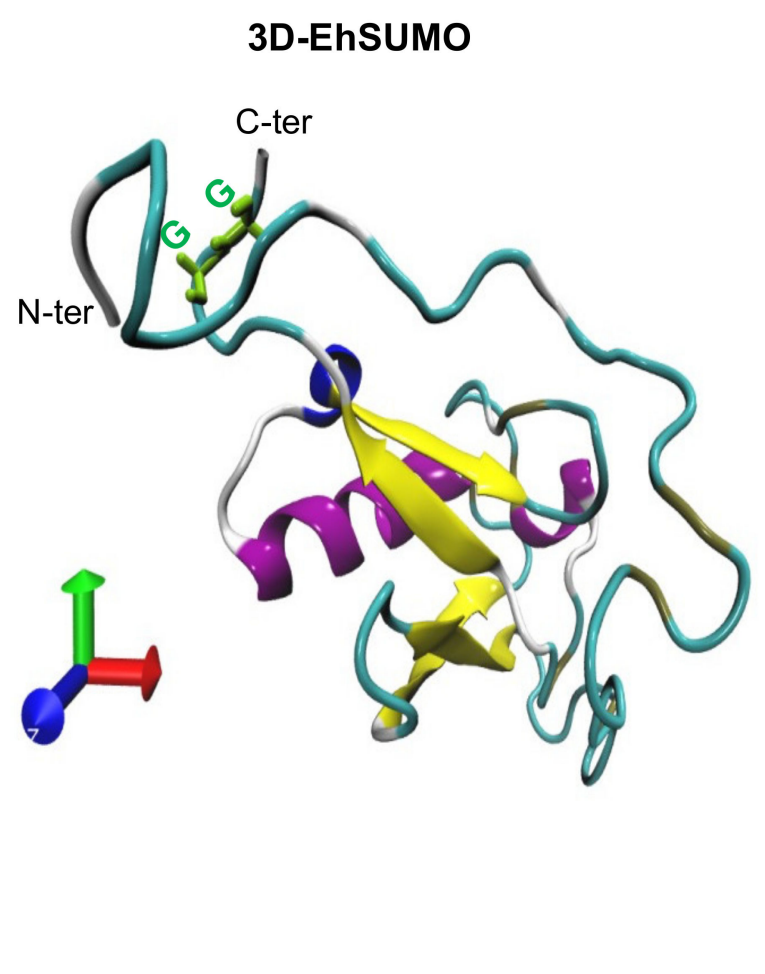

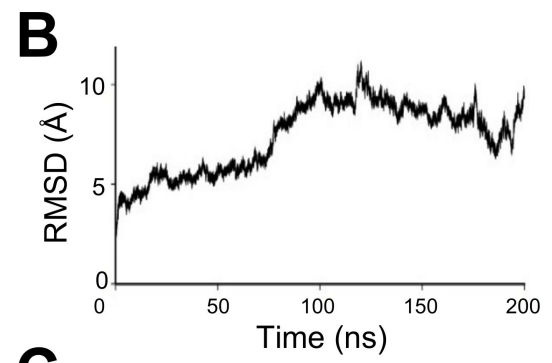

C

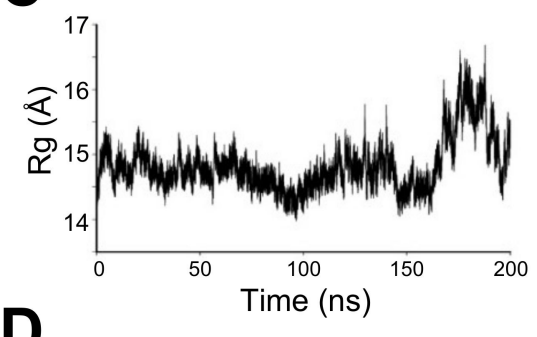

D

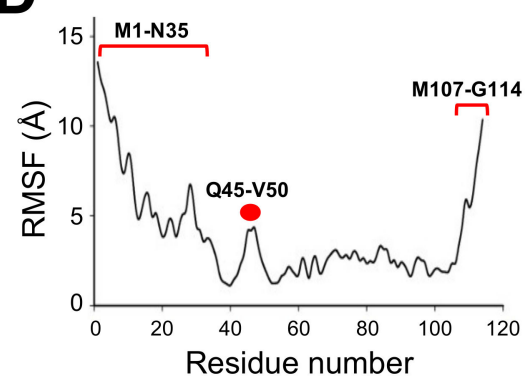

Figure 4. Refined the predicted 3D structure of EhSUMO and MDS. (A) Model of EhSUMO presenting the best C-score after $200 \mathrm{~ns}$ of MDS. The N- and C-terminus regions, as well as the GG residues, are indicated. (B-D) The structural analysis of MDS was carried out by RMSD (B), the radius of gyration (C), and RMSF (D). The most flexible regions are indicated in red dot and brackets.

RMSD evaluates the system convergence during MDS and indicates whether the values follow a normal distribution [31]. EhSUMO reached the equilibrium after $100 \mathrm{~ns}$ (Figure 4B). The Rg values define the protein expansion and compactness. Rg revealed that EhSUMO compacted at the first $100 \mathrm{~ns}$, then, it suffered an expansion from 100 to $135 \mathrm{~ns}$, and in the last $60 \mathrm{~ns}$ of the trajectory, EhSUMO again evidenced expansion (Figure 4C), probably due to the presence of the GG region and its context. Three principal regions appeared as the most flexible areas, detected by RMSF analysis: one at M1 to N35 amino acids composed by coils and turns with non-secondary structure, explaining its higher fluctuation; the second one from Q45 to V50, in a loop, and the last one at the N-terminus from M107 to G114 residues, formed by coils and turns, with a high fluctuation (Figure 4D). Our findings confirm that the 3D model of EhSUMO has the structure predicted for other SUMO orthologues.

2.3. Under the Stimulus of Erythrocytes, EhSUMO Moves from the Cytoplasm to the Target Cell Adherence Points, Phagocytic Cups, and Phagosomes

According to the in silico data, EhSUMO could be a bona fide orthologous of SUMO genes, thus, we proceeded to clone the full gene and express it in Escherichia coli. After purification, the recombinant protein (rEhSUMO) was used to obtain rat $\alpha$-EhSUMO polyclonal antibodies that in western blot assays detected a $17 \mathrm{kDa}$ band in agreement to the 12.6 kDa predicted for EhSUMO plus the histidine label (Figure 5A). 
A

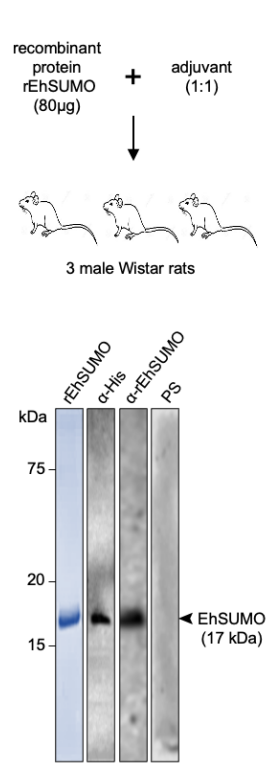

B basal condition erythrophagocytosis:
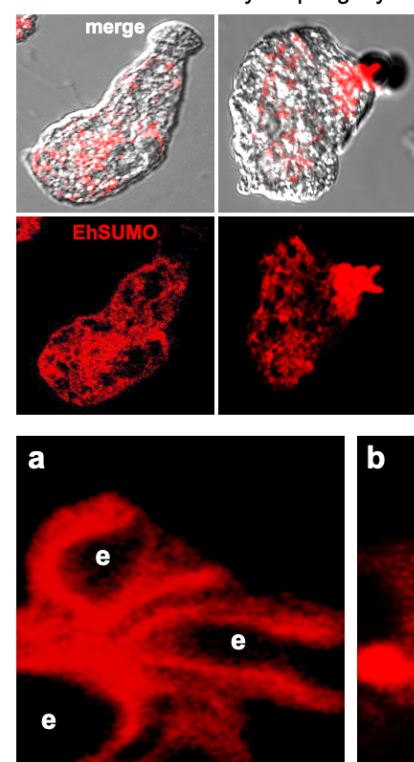
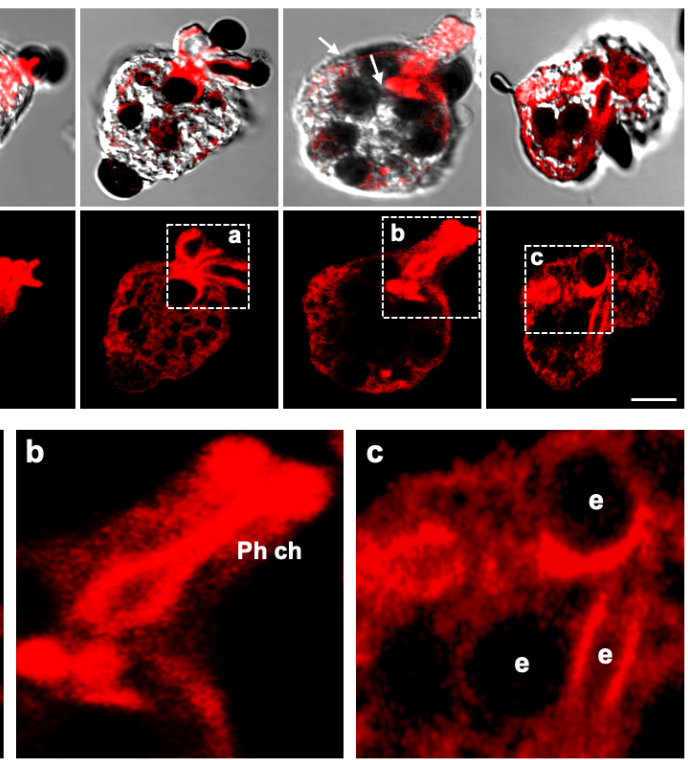

C
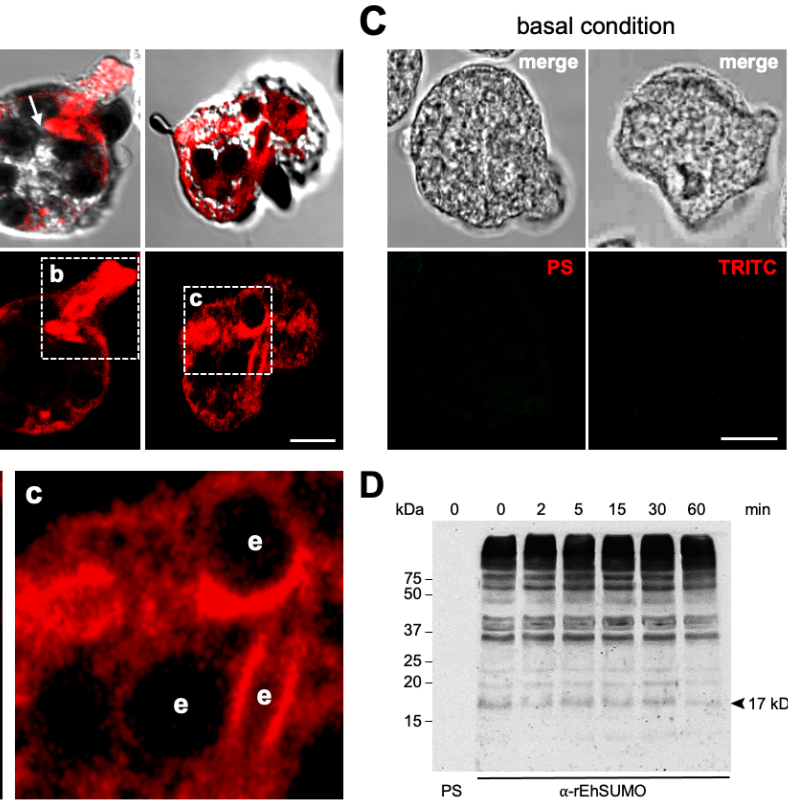

D

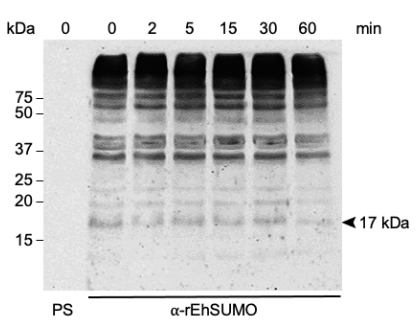

Figure 5. Cellular location of EhSUMO during phagocytosis. (A) Immunization scheme to produce $\alpha$-EhSUMO antibodies, probed in western blot assays, using bacterial lysates. $\alpha$-His antibody: positive control. Pre-immune serum (PS): negative control. Lane 1: rEhSUMO stained with Coomassie blue. Numbers at left: molecular weight standards. (B) Confocal microscopy of trophozoites in basal condition and after erythrophagocytosis, using $\alpha$-EhSUMO antibodies. Squares: different structures formed during phagocytosis magnified in $(\mathbf{a}-\mathbf{c})$. (a) Structure with the form of a conduit or channel. (b) Phagocytic channel (Ph ch). (c) The elongated structure surrounding a phagocytosed erythrocyte. e: erythrocytes. Scale bar $=10 \mu \mathrm{m}$. (C) Negative controls: trophozoites in basal conditions incubated with PS or only with the secondary antibody (TRITC). (D) Western blot analysis of trophozoites lysate in basal condition (0 min) and after erythrophagocytosis, using PS or $\alpha$-EhSUMO antibodies. Number at left: molecular weight standards.

Under confocal microscopy analysis, EhSUMO was located by specific antibodies and fluorescein-labeled rabbit $\alpha$-rat secondary antibodies. In basal conditions, EhSUMO appeared dispersed in the cytoplasm, close to the internal plasmatic membrane, and around vesicles/vacuoles, some label was detected free in the cytoplasm, conjugated or non-conjugated to other molecules, or both (Figure 5B). After the erythrocytes stimulus was given, EhSUMO moved to the pole where the trophozoites contacted the prey; and fluorescence was more intense in the recently molded phagocytic channels. Fluorescence was also found around the ingested erythrocytes and in large phagosomes containing three or more erythrocytes (Figure 5B). Magnification of these structures revealed the bizarre figures formed in plasma and internal membranes during phagocytosis (Figure 5Ba-c). Negative controls such as pre-immune serum and only secondary antibody gave non fluorescent signals (Figure 5C). Surprisingly, western blot assays of samples obtained after different times of erythrophagocytosis did not reveal changes in the quality and quantity of proteins. The $\alpha$-EhSUMO antibodies recognized at least 10 bands from around 17 to more than $240 \mathrm{kDa}$. Some of these bands might include more than one target protein or contain SUMO polymers (Figure 5D). The faint band of around $17 \mathrm{kDa}$ could correspond to unconjugated EhSUMO, although Vranych and Merino [19] reported that free SUMO appeared in G. lamblia with higher molecular weight than the predicted one, which has been confirmed in several systems [32,33]. Intriguingly, the purified recombinant EhSUMO protein migrates at the predicted molecular weight, suggesting that inside the cell, other factors could alter its structure or migration. SUMOylation and deSUMOylation are dynamic events, and the detection of small differences through the phagocytosis kinetics might be hard. Despite this, our results evidence that under the erythrocyte stimulus, EhSUMO moves, together with certain proteins, from the cytoplasm to the phagocytic pole 
and vesicles, suggesting that SUMOylation could be a switch that prepares proteins to perform their role through phagocytosis.

\subsection{In Silico Analysis Reveals Sumoylation Sites in ESCRT-III and EhADH Proteins}

One of the long-term goals of our research group has been to discover events governing phagocytosis in E. histolytica. Therefore, we investigated if the ESCRT-III proteins and EhADH [17,34], possess sequences that make them susceptible to be SUMOylated. We employed the GPS-SUMO software [35] that predicts attraction sites for SUMO in proteins by an algorithm obtained from 983 SUMOylation sites in 545 proteins and 151 SUMO interaction motifs (SIMs) present in 80 proteins [36]. GPS-SUMO software detected putative SUMOylation sites in EhVps2, EhVps24, and EhADH sequences (TKLP, VKNE, QKAA, respectively) (Table 3). Although only EhVps24 conserves the canonical SUMO-binding sequence, the three proteins have the $\mathrm{K}$ in the right position. In addition, according to the software, Vps20, EhVps32, and EhADH have SIMs (VTDLDQK IVDLD RQIRQNI, NNEKSHE IGDLL GEDLQDI, EYNSKAQ VILND SKKCES, respectively) (Table 3). SIMs facilitate the non-covalent conjugation of the protein to SUMO that increases its capacity for SUMOylation, altering the target protein surface and allowing its interaction with distinct molecules [37]. In addition, other proteins related to phagocytosis, such as EhVps26, EhVps35, EhCaBP1, heat shock protein 70, phosphatidylinositol phosphate kinase, EhRabB, EhRab7, EhNPCs, EhPATMK, EhABPH, myosin heavy chains 1 and Gal/GalNAc lectin heavy subunit, among others, are also predictable to be SUMOylated or interact with SUMO protein (Table S1). These in silico results, predict that proteins involved in phagocytosis such as EhADH and ESCRT members are susceptible to being SUMOylated.

Table 3. Predicted SUMOylation sites of ESCRT-III and EhADH proteins.

\begin{tabular}{|c|c|c|c|c|c|c|}
\hline ESCRT Complex & Protein & Position & Peptide/Sequence & Score & Site & Protein Size (aa) \\
\hline \multirow{4}{*}{ ESCRT-III } & EhVps2 & 117 & RKVNEATKLPAMQKV & 24,671 & SUMOylation & 246 \\
\hline & EhVps20 & $32-36$ & VTDLDQKIVDLDRQIRQNI & 65,754 & SIM & 206 \\
\hline & EhVps24 & 176 & EGGIEAVKNEVIAES & 43,439 & SUMOylation & 205 \\
\hline & EhVps32 & $133-137$ & NNEKSHEIGDLLGEDLQDI & 64,005 & SIM & 204 \\
\hline ESCRT & EhADH & 154 & QAAGAFQKAADCAQL & 25,680 & SUMOylation & 687 \\
\hline Accessory Proteins & - & $366-370$ & EYNSKAQ VILND SKKCES & 58,036 & SIM & - \\
\hline
\end{tabular}

\subsection{EhADH Protein Interacts with EhSUMO}

In addition to the SUMOylation sites deciphered by the GPS-SUMO software [35], the secondary structure of EhADH unveiled putative SUMOylation sites at its Bro1 domain (154 amino acid) and the linker region, from 366 to 370 residues (Figure 6A). Docking modeling analysis using the 3D model of EhSUMO, obtained here, and the 3D model of EhADH previously published [31], suggested that EhADH interacts with EhSUMO by an $\mathrm{R}$ rich region, close to the predicted SIM site, making contact also through the S660 to V662 residues, at the C-terminus, whereas EhSUMO interacted with EhADH mainly through the $\mathrm{N}$-terminus with a $\Delta \mathrm{G}=-833.4$ (Figure 6B).

Immunofluorescence assays using $\alpha$-EhSUMO and $\alpha$-EhADH antibodies, uncovered, in basal conditions, dissimilar fluorescent patterns of EhADH and EhSUMO. However, merging images revealed colocation of both proteins at pseudopodia and in regions close to the plasma membrane (Figure 6C). Immunoprecipitation assays using $\alpha$-EhSUMO antibodies and trophozoites lysates confirmed this association. By western blot assays, $\alpha$-EhSUMO antibodies revealed the EhSUMO protein in the input (total trophozoites proteins), and in immunoprecipitates. Similarly, the $\alpha$-EhADH antibodies unveiled the EhADH protein in both samples (Figure 6D). These results strongly suggest that both proteins associate with each other, interacting directly or indirectly. 
A

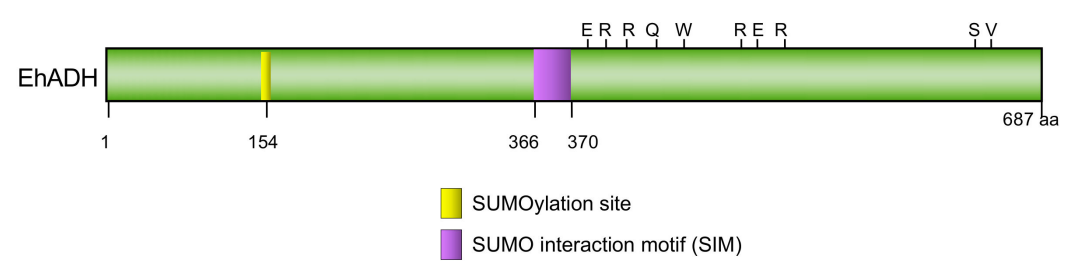

C
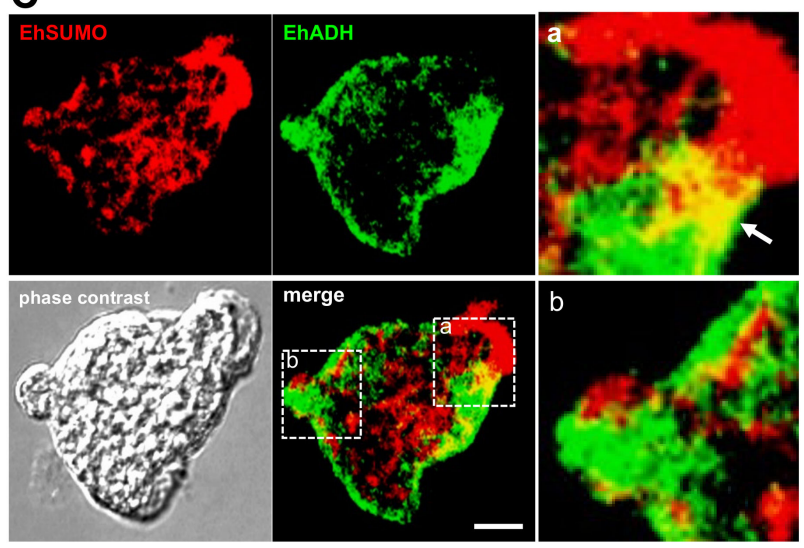

B

D
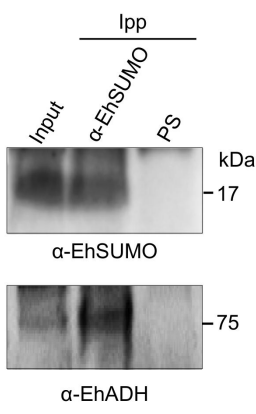

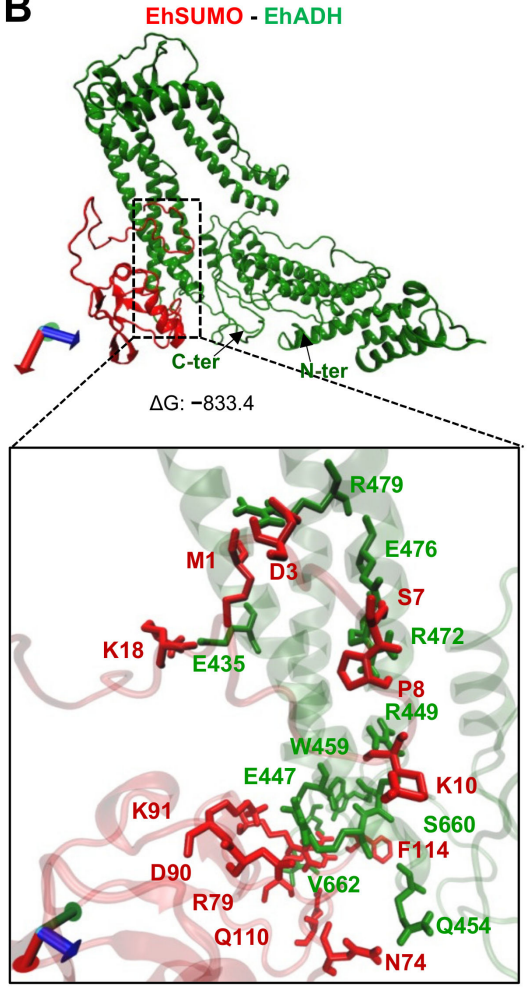

Figure 6. Association of EhSUMO and EhADH. (A) Schematic representation of EhADH protein with SUMOylation (yellow) sites and SIM sites (purple). (B) Molecular docking between predicted EhSUMO (red) and predicted EhADH (green). Square in the bottom: magnification of the interacting residues. Axes: $x$, red; $y$, green; $z$, blue. (C) Immunofluorescence assays of trophozoites under basal conditions using $\alpha$-EhSUMO (red) and $\alpha$-EhADH (green) antibodies. Regions in squares are magnified. Arrow: colocalization area. Scale bar $=10 \mu \mathrm{m}$. (D) Western blot of Immunoprecipitates using trophozoites lysates and $\alpha$-EhSUMO antibody or pre-immune serum (PS) and probed with $\alpha$-EhSUMO or $\alpha$-EhADH antibodies. Numbers at right: molecular weight of immunodetected proteins.

\subsection{Colocation of EhSUMO and EhADH Increases during Phagocytosis}

To investigate the cellular fate of EhSUMO and EhADH during phagocytosis, trophozoites were prepared for immunofluorescence assays and examined through confocal microscopy after different times of phagocytosis. At 5 min, EhSUMO was detected in the place of contact where erythrocytes were being ingested (Figure 7A,B), forming the peculiar membranous structures in the phagocytic channel (see Figure 5). It also appeared around ingested erythrocytes and surrounding big pockets that could be the pre-phagosomes formed to receive the red blood cells from other endosomes (Figure 7A). In some images, EhADH did not show up in the same region of the phagocytic channel that EhSUMO did, although laser sections revealed its presence in other places of this structure, as published before [38]. Large bags in the cytoplasm, that could correspond to putative pre-phagosome structures, were also enlightened by the $\alpha$-EhADH antibodies, inside and surrounding them, and the label was also detected around the ingested erythrocytes (Figure 7A). At 15 and $30 \mathrm{~min}$ of phagocytosis, the EhADH and EhSUMO colocation increased (Figure 7), and at $60 \mathrm{~min}$, both proteins moved to the internal plasma membrane and remained around the ingested erythrocytes. The erythrocytes-containing structures exhibited different sizes and numbers of erythrocytes inside. Some of them emerged stained only by $\alpha$-EhSUMO or by $\alpha$-EhADH antibodies, suggesting differential participation for SUMOylated proteins during the maturation of endosomes/phagosomes. The three conditions were observed: EhSUMO and EhADH separated and both proteins associated. Quantification of fluorescence colocation confirmed that it increased through the phagocytosis kinetics (Figure 7C), suggesting that the EhSUMO-EhADH association enhance during this virulence-related event. 


\subsection{In Silico Analysis Discloses Interaction between EhVps32 and EhSUMO}

EhVps32 has a predicted molecular weight of $22.4 \mathrm{kDa}$, although due to its structure and charge of amino acids, it migrates at $32 \mathrm{kDa}$ in SDS-PAGE [14]. Its secondary structure exhibits a SIM (NNEKSHE IGDLL GEDLQDI) from the 134 to 137 amino acids (Figure 8A), whereas its predicted 3D structure, obtained from the I-TASSER server, presents three $\alpha$-helices, after $200 \mathrm{~ns}$ MDS by NAMD software in a soluble environment (Figure $8 \mathrm{~B}$ ). The model selected according to the C-score and the best Ramachandran plot values was employed for these analyses.

A

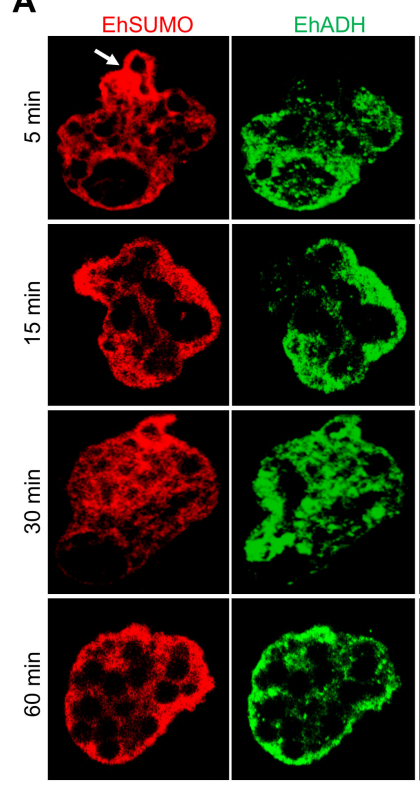

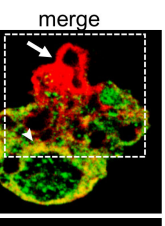
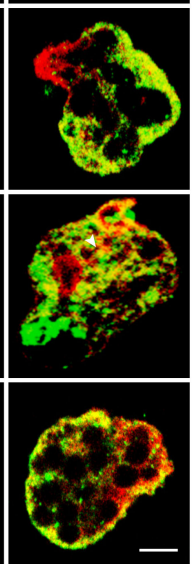

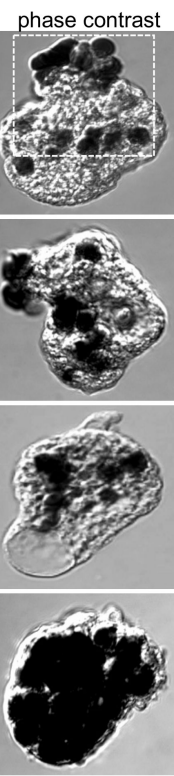

B
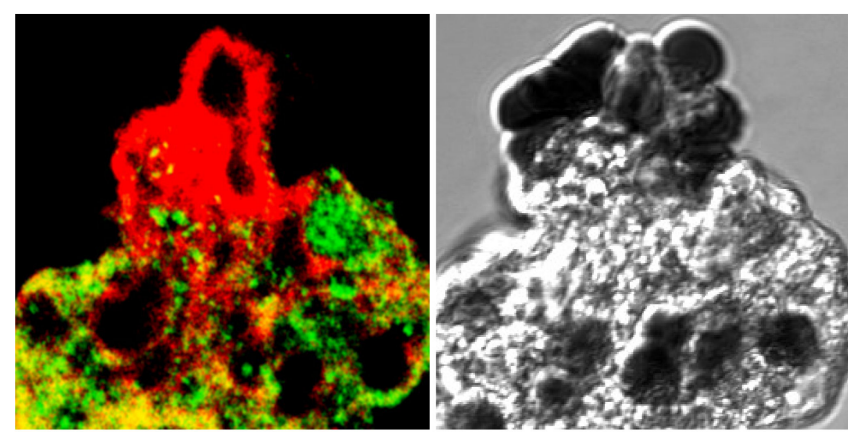

C

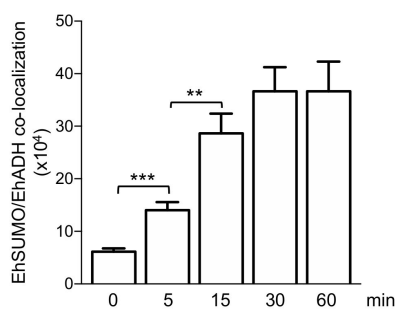

Figure 7. Location of EhSUMO and EhADH during phagocytosis. Trophozoites were incubated Figure 5. 15, 30, and 60 min with erythrocytes and processed for confocal microscopy. (A) Immunofluorescence assays using $\alpha$-EhSUMO (red) and $\alpha$-EhADH (green) antibodies. Arrow: EhSUMO in erythrocytes being phagocytosed. Scale bar $=10 \mu \mathrm{m}$. (B) Magnification of squares in (A). (C) Quantification of EhSUMO and EhADH colocalization in the whole cells. $\left(^{* *}\right) p<0.01\left({ }^{* * *}\right) p<0.001$.

The Ramachandran plot showed $92.98 \%, 69.47 \%$, and $3.16 \%$ of the amino acids in the favored, allowed, and outside the allowed regions, respectively. Besides, the RMSD analysis showed that EhVps32 reached the equilibrium at 100 ns (Figure 8C), whereas the Rg values, indicated that it compacted through the trajectory (Figure 8D), exhibiting two regions as the most flexible areas, located at E35 to K59 amino acids and the between N101E150 residues, respectively. Docking analysis predicted that EhVps32 and EhSUMO contact each other with a $\Delta G=-899.24$ (Figure 8F). As in the case of EhADH, the interaction was performed in a wider region than the predicted one, distributed along the whole protein. The site was composed of three $\mathrm{N}$, one close to the amino terminus, the other to the C-terminus, and the third one at the RNMK motif (Figure 8F), while EhSUMO contacted EhVps32 through its N-terminus (Figure 8F). These bioinformatics data predict the association between EhSUMO and EhVps32 proteins.

\subsection{Immunofluorescence and Immunoprecipitation Experiments Confirm the EhSUMO and EhVps32 Interaction}

Confocal images of trophozoites in basal conditions, evidenced colocation of EhSUMO and EhVps32 around vesicles/vacuoles, in the inner plasma membrane, in the origin of the pseudopodia, and extensively in clumps in the cytoplasm (Figure 8G). Immunoprecipitation assays, using $\alpha$-EhSUMO antibodies revealed EhSUMO and EhVps32 in the immunoprecipitates (Figure $8 \mathrm{H}$ ). All these experiments showed an association between EhSUMO and EhVps32, although it could be direct or indirect. 
A

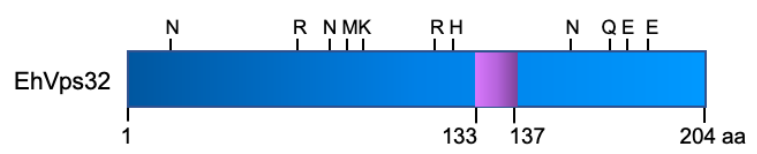

C

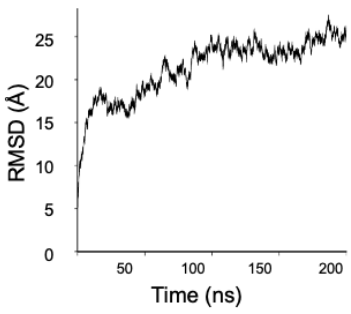

$\mathbf{G}$
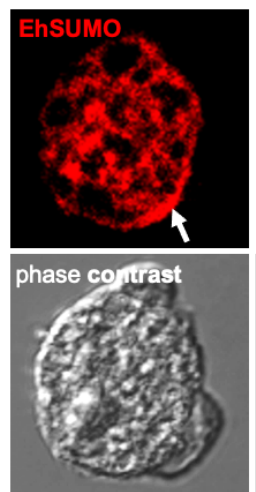

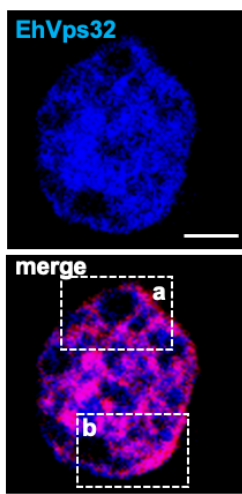

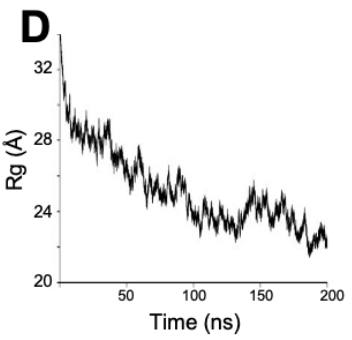

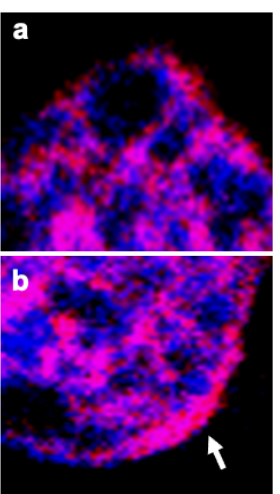

Predicted SUMO interaction motif (SIM)

$\mathbf{B}$
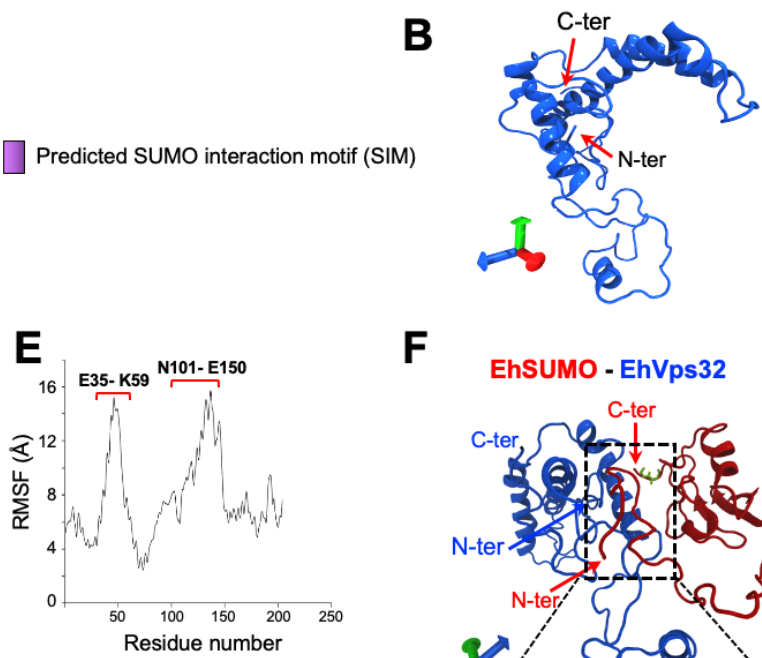

$\mathbf{F}$

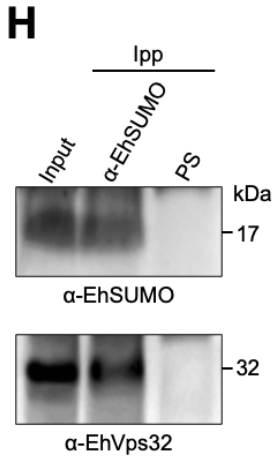

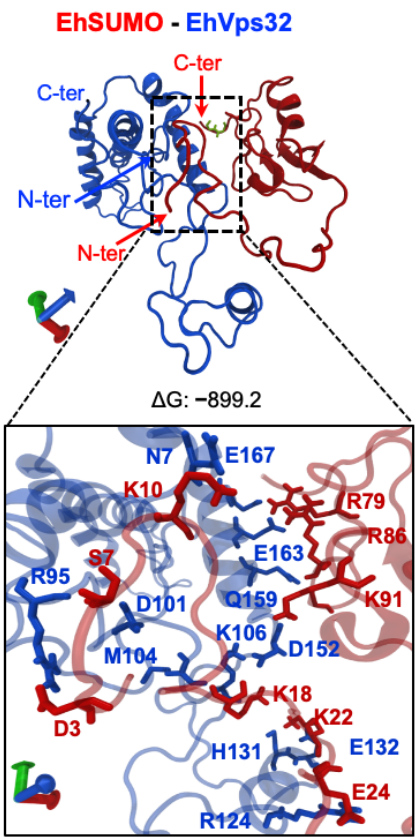

Figure 8. Association of EhSUMO and EhVps32. (A) Schematic representation of SIM (purple) site in EhVps32 protein. (B) Predicted model of EhVps32 after 200 ns of MDS. The N- and C-terminus regions are indicated. Structural analysis of MDS carried out by (C) RMSD, (D) radius of gyration, and (E) RMSF. Red brackets indicate the most flexible regions. (F) Molecular docking of EhSUMO (red) and EhVps32 (blue). Square: magnification of the interacting residues. Sticks in green indicate the glycines in EhSUMO. Axes: x, red; y, green; z, blue. (G) Immunofluorescence assays of trophozoites under basal conditions using $\alpha$-EhSUMO (red) and $\alpha$-EhVps32 (blue) antibodies. Squares: magnification of proteins colocalization ( $a, b$, and arrow). Arrow: area of colocalization in the internal plasma membrane. Scale bar $=10 \mu \mathrm{m}$. (H) Trophozoites in basal conditions were lysed and immunoprecipitated using $\alpha$-EhSUMO antibody or pre-immune serum (PS) and immunoprecipitated proteins were analyzed by western blot using $\alpha$-EhSUMO or $\alpha$-EhVps32 antibodies. Numbers at right: molecular weight of immunodetected proteins in western blot assays.

\subsection{Interaction between EhVps32 and EhSUMO Continues through Phagocytosis}

Through phagocytosis, confocal images using the $\alpha$-EhSUMO antibodies, disclosed the same membranous structures described above, and the small vesicles surrounding larger endosomes/phagosomes (Figure 9A,B). Whereas the $\alpha$-EhVps32 antibodies appeared around the erythrocytes, in the phagocytic bags, and close to the internal plasma membrane (Figure 9A), as described [17]. Both proteins exhibited an extensive colocation, suggesting that EhSUMO is associated with EVps32 or other proteins interacting with EhVps32, which could include the ESCRT-III members and EhADH (Figure 7). However, red spots appeared around and near the red blood cells (Figure 9), showing that EhSUMO also conjugates to other proteins that are not in contact with EhVps32. In contrast to the experiments performed with $\alpha$-EhADH and $\alpha$-EhSUMO antibodies, colocation of EhVps32 and EhSUMO was stronger, and it was maintained and even slightly increased during phagocytosis (Figure 9A,B). Quantification of the fluorescent label in colocation confirmed this (Figure 9C). 

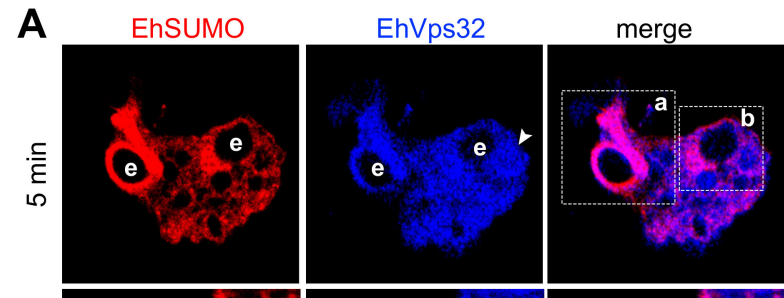

phase contrast
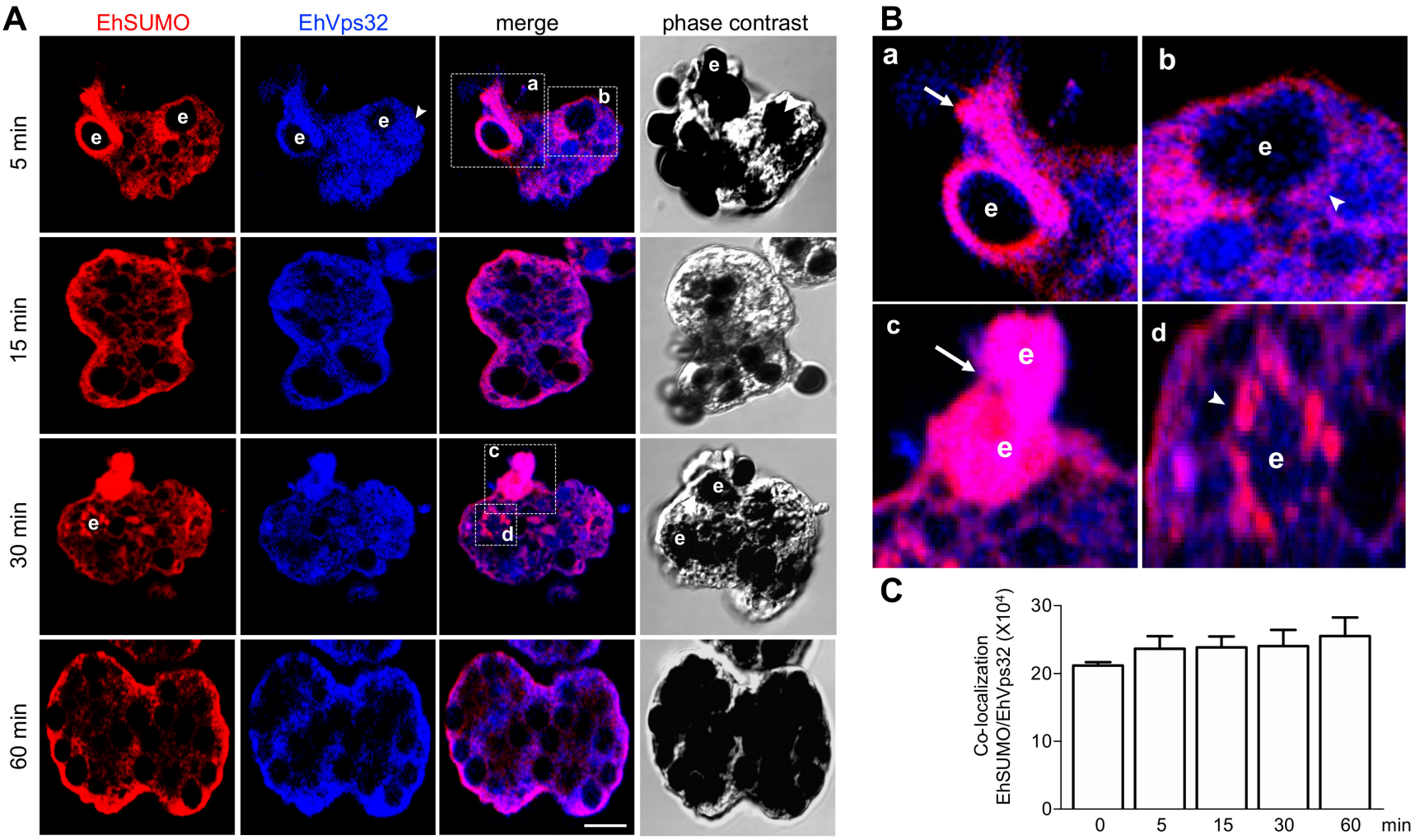

C

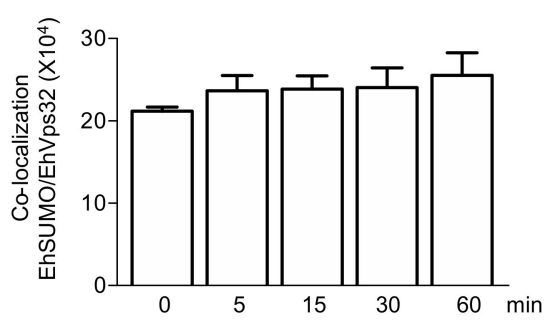

Figure 9. Location of EhSUMO and EhVps32 during phagocytosis. Trophozoites were incubated for 5, 15, 30, and 60 min with erythrocytes (e) and processed for confocal microscopy. (A) Immunofluorescence assays, using $\alpha$-EhSUMO (red) and $\alpha$-EhVps32 (blue) antibodies. Scale bar $=10 \mu \mathrm{m}$. (B) Magnification of squares presented in (A). Arrow: colocalization of proteins in a channel-like structure (a) and in erythrocytes (c). Arrowhead: colocalization of both proteins surrounding a vesicle with erythrocytes (b,d). (C) Quantification of EhSUMO and EhADH colocalization in the whole cells.

\subsection{EhSUMO Knocked-Down Trophozoites Exhibited Diminished Adhesion, Erythrophagocytosis and Cytopathic Effect in Comparison to the Wild Type Strain}

To deepen the importance of SUMOylation in phagocytosis and other virulence properties of E. histolytica, we silenced the EhSUMO gene, using double-stranded RNA (dsRNA), expressed in bacteria, [39]. After incubation of trophozoites for $24 \mathrm{~h}$ with the dsRNA, lysates from silenced (KD) and control trophozoites were submitted to western blot assays. Protein patterns of control in KD trophozoites notably differed (Figure 10A). In control, bands from about $17 \mathrm{kDa}$ to more than $240 \mathrm{kDa}$ reproducibly appeared in the nitrocellulose membranes (like it is shown in Figure 5). However, in the KD trophozoites, bands were fainter, and some proteins of high molecular weight did not appear (Figure 10A), suggesting a lower SUMOylation of certain proteins. The antibodies against the nuclear protein EhPCNA evidenced that the amount of protein used in both lanes of the gel was similar, and degradation was not detected, at least for this protein (Figure 10A).

Polyclonal antibodies against an exposed peptide in the EhADH structure ( $\alpha$ EhADH18; 494-KFRQFENDIKLLCEGNIQ-513 residues) (Figure 10B), recognized in the control trophozoites, the $75 \mathrm{kDa}$ band of EhADH and the 112-124 kDa bands representing the distinct conformations of the EhCPADH complex. However, very faint bands were detected in KD cells (Figure 10A). The specificity of the $\alpha$ EhADH18 was probed by confocal microscopy assays, using pre-immune serum, or by incubating only with secondary antibodies (Figure 10C). The EhCPADH complex is formed by the association of EhADH with the EhCP112 cysteine protease $[31,34]$ and it acquires distinct conformations, presenting slight differences in migration in SDS-PAGE. It has been reported that SUMOylation-deSUMOylation alters protein conformation, hiding relevant epitopes for protein binding and antibody recognition [40]. To explore this idea, we used two distinct polyclonal antibodies, directed against 
the full-length EhADH protein $(\alpha-\mathrm{EhADH})$ and another against the 18 amino acids epitope at the C-terminus of the protein. In agreement with earlier results [34,41], in the control trophozoites, $\alpha$-EhADH antibodies recognized the 112-124 kDa bands corresponding to the EhCPADH complex [41], but free EhADH was not visible. However, the $\alpha$-EhADH antibodies detected the $75 \mathrm{kDa}$ band corresponding to the free EhADH and the EhCPADH complex (Figure 10A). In contrast, the $\alpha$-EhADH 18 antibody did not react with the corresponding bands, suggesting that the epitope was not exposed. These results support the hypothesis of alteration of EhADH conformation, probably due to the lack of efficient SUMOylation. Nevertheless, this assumption needs more experiments to be precisely confirmed. Interestingly, EhVps32 appeared likewise in KD and control trophozoites, also serving as an internal control of the amount and integrity of proteins loaded in the gel. Although we would expect distinct molecular weights between the SUMOylated and non-SUMOylated EhVps32, it is possible that during the sample preparation process, the non-covalent binding of SUMO to its target could be destroyed, or that EhSUMO could be indirectly bound to EhVps32.

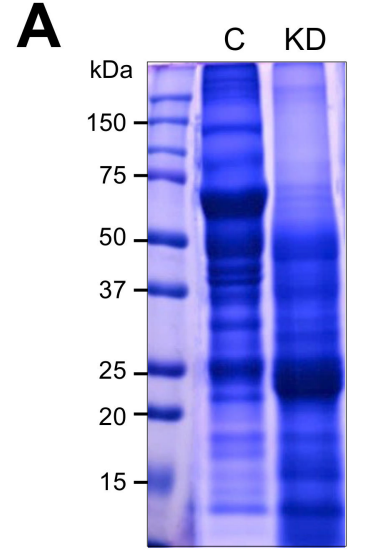

B

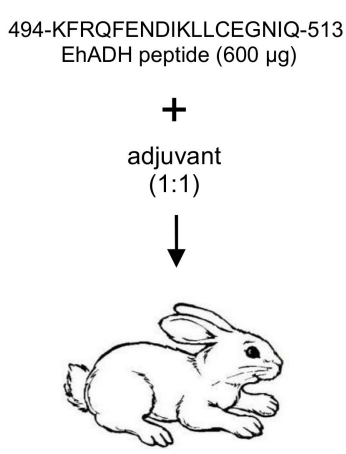

New Zeland rabbit

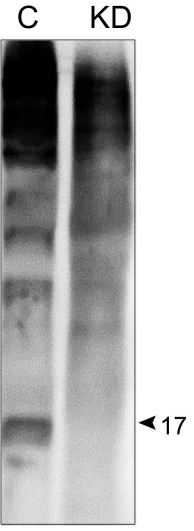

$\alpha$-EhSUMO

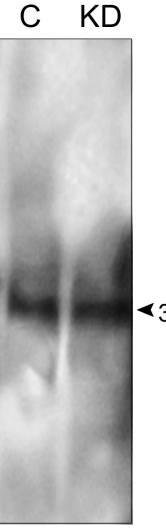

$\alpha$-EhPCNA

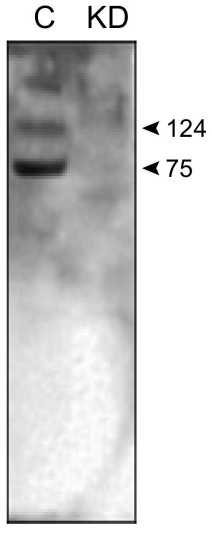

$\alpha-E h A D H 18$
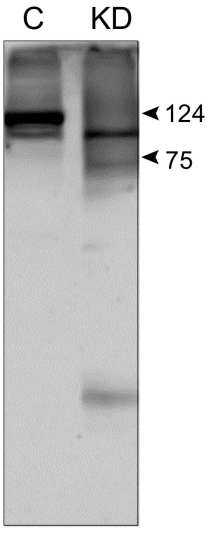

$\alpha-E h A D H$
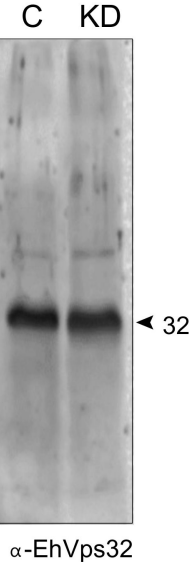
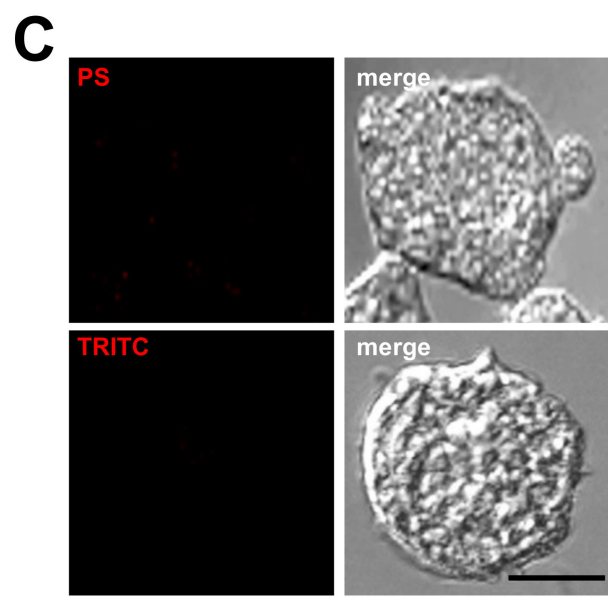

Figure 10. Effect of EhSUMO knock-down in the expression of EhADH and EhVps32 proteins. Trophozoites were silenced using the pL4440/EhSUMO plasmid as described in materials and methods. (A) Coomassie staining or western blot of lysates from control (C) or EhSUMO-KD trophozoites (KD) in basal condition, using different antibodies: $\alpha$-EhSUMO, $\alpha$-EhADH18, $\alpha$-EhADH, or $\alpha$-EhVps32. $\alpha$-EhPCNA: loading control. Numbers at left: molecular weight standards. Number at right: molecular weight in $\mathrm{kDa}$ of immunodetected proteins. (B) The $\alpha$-EhADH18 antibody generated in rabbits and using an EhADH peptide of 18 residues, was tested in trophozoites lysates (lane 1) and with the recombinant protein EhADH (lane 2). As a control, the pre-immune serum (PS) was employed in trophozoites lysates (lane 3). (C) Confocal images of trophozoites incubated with PS or only with the secondary antibodies (scale bar $=10 \mu \mathrm{m}$ ). 
Next, we evaluated the effect of EhSUMO-silenced trophozoites in their adhesion to and phagocytosis of erythrocytes and the cytopathic effect on MDCK epithelial monolayers. Adhesion and erythrophagocytosis experiments evidenced that in all cases, KD trophozoites adhered and phagocytosed between 32 and 37\% fewer erythrocytes than the wild type (Figure 11A-D). However, differences in their ability to destroy cell monolayers were lightly retarded in KD-trophozoites, in comparison with control parasites (Figure 11E,F).
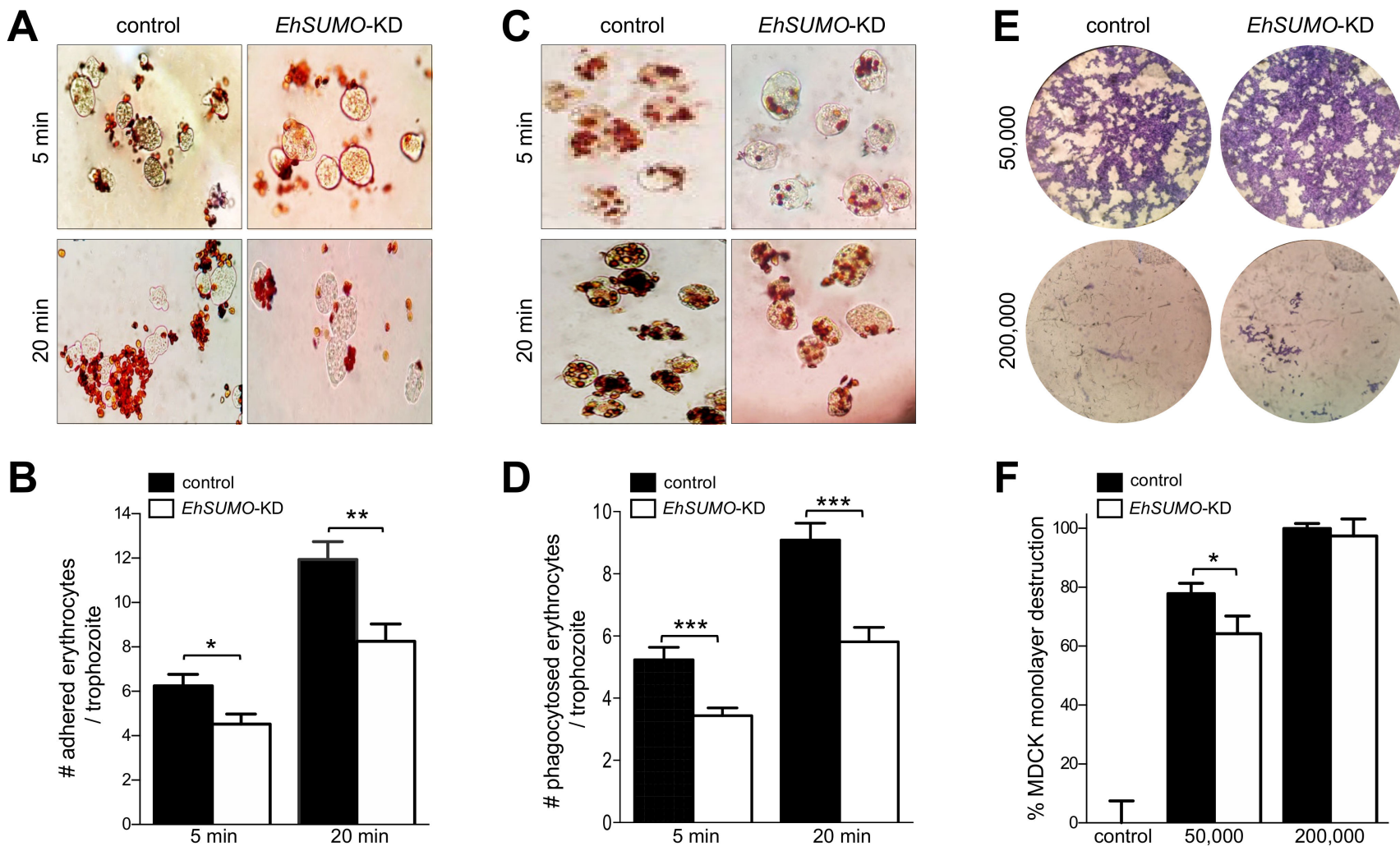

Figure 11. Effect of EhSUMO knock-down in the adhesion, phagocytosis, and cytopathic effect. (A) Novikoff staining of control and EhSUMO-KD trophozoites at 5 and $20 \mathrm{~min}$ of adhesion to erythrocytes. (B) Number of adhered erythrocytes per trophozoite. (C) Novikoff staining of control and EhSUMO-KD trophozoites at 5 and 20 min erythrophagocytosis. (D) The rate of erythrophagocytosis was evaluated by counting the number of erythrocytes per trophozoite. Data represent the median and standard error of 100 trophozoites (E) The MDCK monolayer damage produced by different amounts (50,000 and 200,000) of control and KD-trophozoites was evidenced by methylene blue staining. (F) The destruction of epithelial cells was calculated by measuring the remaining dye concentration in the cell monolayer after contact with trophozoites. Control: MDCK cells non-incubated with trophozoites. Values represent the median and standard error of the three independent experiments. $\left.{ }^{*}\right) p<0.05,\left({ }^{* *}\right) p<0.01,\left({ }^{* * *}\right) p<0.001$.

Laser confocal immunofluorescence experiments verified the effect of EhSUMO silencing in trophozoites. The $\alpha$-EhSUMO antibodies revealed a stronger signal in the control trophozoites than the KD ones. Additionally, the bizarre membranous structures formed by $\alpha$-EhSUMO antibodies were not visible in KD trophozoites during phagocytosis. Besides, in contrast to the western blot assays, $\alpha$-EhADH and $\alpha$-EhVps32 antibodies were less reactive in the KD trophozoites by immunofluorescence assays (Figure 12A). The three proteins appeared associated in different areas in the control, even in basal conditions, but in KD trophozoites, colocation was much lower (Figure 12B,C). During erythrophagocytosis, EhSUMO-deficient trophozoites displayed poor colocalization and a small but significant reduction of the recognition of EhADH and EhVps32 by the antibodies (Figure 13). These findings point to the relevance of SUMOylation in phagocytosis and suggest that proteins are affected in distinct ways by the SUMOylation-deSUMOylation processes. 

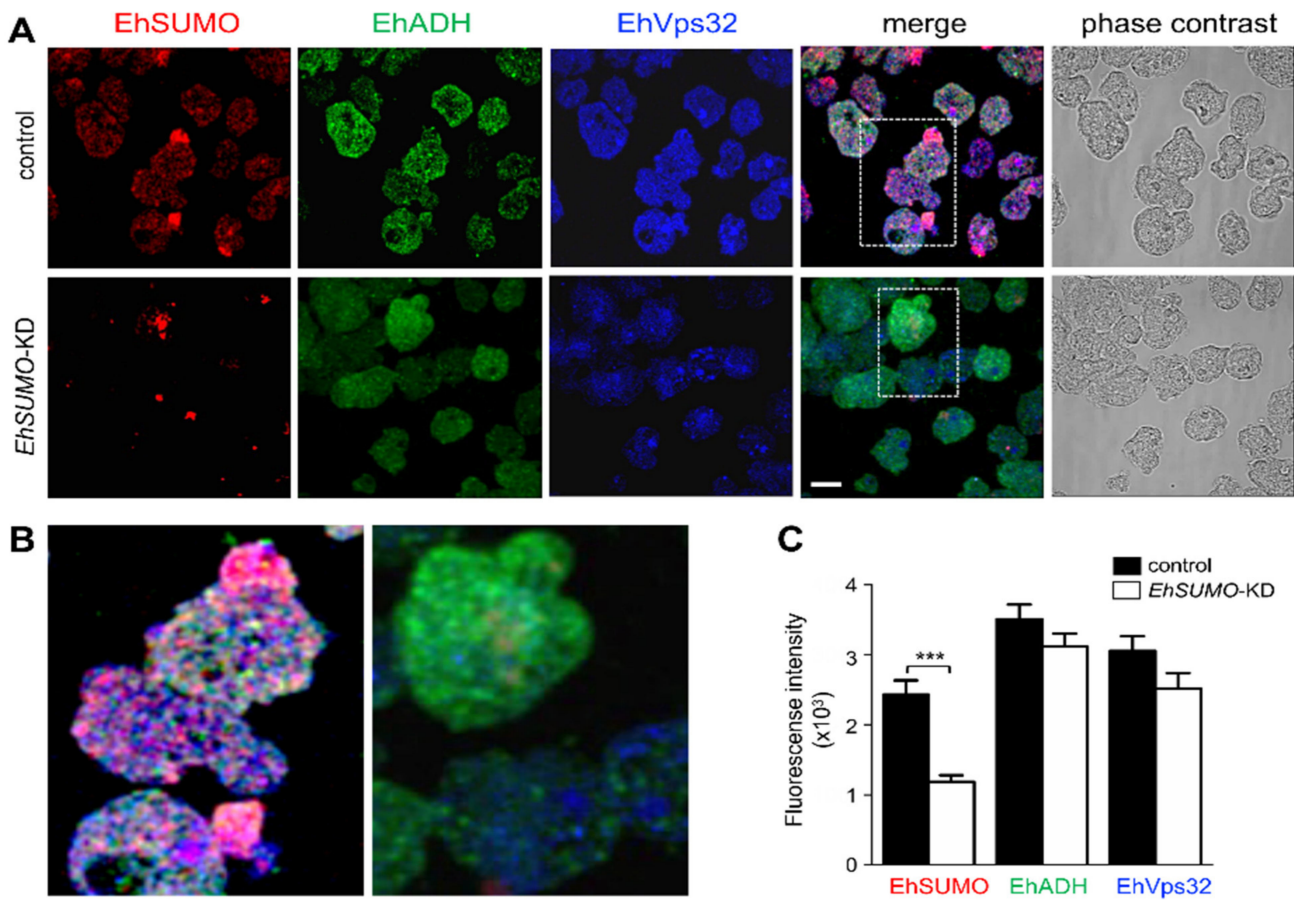

Figure 12. Localization of EhSUMO, EhADH, and EhVps32 in EhSUMO-KD trophozoites in basal conditions. Confocal microscopy of control and KD trophozoites in basal conditions. (A) Representative image of control and EhSUMO-KD trophozoites using $\alpha$-EhSUMO (red), $\alpha$-EhADH (green), and $\alpha$-EhVps32 (blue) antibodies. Scale bar $=10 \mu \mathrm{m}$. (B) Magnification of squares in (A). (C) Fluorescence intensity measured by pixels and corresponding to EhSUMO, EhADH, and EhVps32 in both types of trophozoites. $\left.{ }^{* * *}\right) p<0.001$.
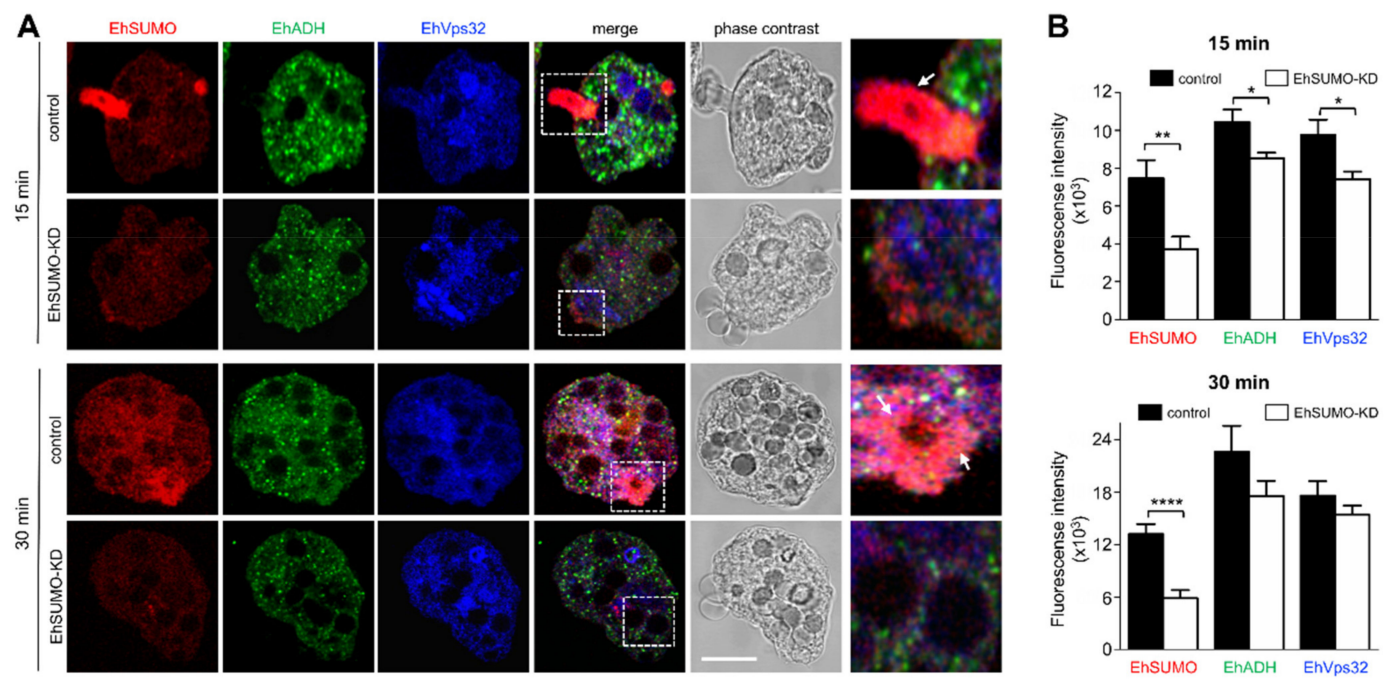

Figure 13. Localization of EhSUMO, EhADH, and EhVps32 in EhSUMO-KD trophozoites during phagocytosis. Erythrophagocytosis kinetics of trophozoites silenced using the PL4440/EhSUMO plasmid. (A) Representative image of control and EhSUMO-KD trophozoites at 15 and $30 \mathrm{~min}$ of phagocytosis using $\alpha$-EhSUMO (red), $\alpha$-EhADH (green), and $\alpha$-EhVps32 (blue) antibodies and analyzed by confocal microscopy. Scale bar $=10 \mu \mathrm{m}$. Right panels: Magnification of squares in merging images. Arrows: phagocytic channel and areas around erythrocytes. (B) Fluorescence intensity measured by pixels and corresponding to EhSUMO, EhADH, and EhVps32 proteins in both types of trophozoites at both times of phagocytosis. $\left(^{*}\right) p<0.05,\left({ }^{* *}\right) p<0.01$ and $\left(^{* * * *}\right) p<0.0001$.

In conclusion, altogether, the results presented here prove the presence of an intronless bona fide EhSUMO gene encoding for a $17 \mathrm{kDa}$ protein that actively participates in phagocytosis. Silencing of the EhSUMO gene affected adhesion, erytrophagocytosis, and poorly 
the cytopathic effect, and disturbed EhADH and EhVps32, supporting the importance of SUMOylation in phagocytosis, a landmark for the parasite virulence.

\section{Discussion}

In this paper, we disclosed and characterized the presence of a SUMO gene and its product in E. histolytica. Then, by bioinformatics analysis, we also found in the AmoebaDB the enzymes required for SUMOylation of target proteins: E1, the activating enzyme, E2, the conjugated one, and E3 the ligase, as well as those participating in deSUMOylation: UIpb1a and UIpb1b. Our data strongly suggest that SUMOylation is a modifier of the parasite proteins, stimulating some of them during phagocytosis. This assumption is supported by bioinformatics screening of many other published proteins of E. histolytica involved in phagocytosis, which present putative SUMOylation sites and the $\Psi \mathrm{KXE} / \mathrm{D}$ binding motif as shown in Table S1. Furthermore, we unveiled the association of EhSUMO, a ubiquitin-like modifier (UbI) protein, with EhADH and EhVps32 proteins, both involved in phagocytosis. Beyond the detection and characterization of EhSUMO in this parasite, the relevance of this work relies on two main aspects: (i) this is the first report on the role of SUMOylation in phagocytosis and the modification of specific proteins participating in this phenomenon, and (ii) the involvement of SUMOylation during phagocytosis highlights the potential use of this knowledge for the development of therapeutics and diagnosis methods to defeat amoebiasis.

Lack of vaccines, reduced chemotherapy options, and the emergence of drug-resistant parasites [42] are challenges presented by diseases caused by protozoa, among these, amoebiasis. PTMs, including UbIs, modify proteins to facilitate their functions, including virulence-related functions (43). UbIs have been widely studied in yeast, plants, and Mammals [43,44], but little is known on their role in protozoan parasites, highly divergent organisms with characteristics that might be investigated to understand their evolutionary process and their virulence mechanisms [45,46]. Ubls impact the regulation of cellular functions such as cell cycle progression [11], transcription [47,48], stress responses [49], DNA damage repair [50], cell signaling [22], nuclear transport [51], and autophagy [43]. By findings reported here, we add to this list, an old event, found now to be regulated by SUMO: the phagocytosis, involved in damage produced by E. histolytica trophozoites.

In E. histolytica, Arya et al. in 2012 [52] reported a bioinformatics study on UbIs modifiers and their conjugated enzymes, and recently, Kumari et al. In 2018 [53] found a $\mathrm{UBC}$ /Ube2g2 protein connected with the plasma membrane and phagocytosis in trophozoites. Besides this, we have not found reports on SUMOylation in this parasite. By in silico analysis, we detected EHI_170060 contig that presents the characteristics described so far for SUMO. In the phylogenetic tree, EHI_1700060 product (EhSUMO) appeared close to T. cruzi and D. discoideum orthologues. However, we used here as templates the yeast and human SUMO-2 proteins, because they have been extensively studied, their 3D structures are well known, and crystal is available. HsSUMO-2 forms stable polymeric chains that also are susceptible to poly-ubiquitination, a signal for proteasome degradation [54]. This effect is given by the $\mathrm{K} 11$ of the $\Psi \mathrm{KxE} / \mathrm{D}$ consensus motif that allows the formation of poly-SUMO chains, absent in HsSUMO-1. Although we have not studied its relevance of this $\mathrm{K}$ in trophozoites, EhSUMO possesses the K amino acid at the motif $\Psi \mathrm{KxE} / \mathrm{D}$, but at K22. These facts and others, including the MDS analysis [1,55], support the identity and nature of EhSUMO.

Docking of EhADH and EhSUMO, and EhVps32 and EhSUMO, predicted that EhSUMO uses different motifs in the protein target to join to other proteins, but targets suggested by our results could need fine-tuning of punctual mutations to precisely determine the binding sites. However, the confocal images evidenced that EhADH and EhVps32 efficiently bind, directly or indirectly, to EhSUMO, and that SUMOylation influences their cellular location, although we cannot discern how much of the changes were due to the phagocytosis event and how much to the SUMOylation process. Nevertheless, the fact that KD trophozoites in basal conditions did not display EhADH close to the plasma membrane or in pseudopodia, 
suggests that EhADH needs to be SUMOylated to find its cellular position. Confocal assays using control and KD trophozoites, support this assumption. Altogether, these results point out the hypothesis that the equilibrium between PTM proteins and their unmodified state modulates the fate and function of the target substrates during phagocytosis, granting the fine-tuning of the cellular mechanisms needed for life.

Except for EhADH and EhVps32, we could not disclose changes in the amount and nature of the proteins that are SUMOylated during phagocytosis, but SUMOylationdeSUMOylation is a highly dynamic process, and undetectable changes could be occurring. The multiple and speedy changes produced during this phenomenon were evidenced by the images obtained using $\alpha$-EhSUMO antibodies that uncovered the active participation of EhSUMO. The images revealed the extensive membrane changes accordingly to the moment of erythrocyte's contact and ingestion during the intense vesicular trafficking accelerated by phagocytosis. We did not find a single repetitive bizarre figure in a trophozoite or the total population, corroborating the dynamics of the event. SUMOylation alters not only the cellular location of the target protein, but changes the protein conformation, and consequently, their affinity to other proteins [56]. This has been studied mainly in mammalian cells and yeast, but little in parasites, even when these events might be part of their virulence mechanisms.

The change of EhADH conformation was suggested by the lack of recognition by the $\alpha$-EhADH18 antibodies in KD trophozoites. To discard protein degradation, we used a polyclonal antibody directed to the full-length EhADH protein that detected the complex in both types of trophozoites and reacted with the $75 \mathrm{kDa}$ band, evidencing the integrity of the protein. We suspect that the SUMOylation could produce stability on EhADH, but when EhSUMO is diminished, the non-SUMOylated protein could change its structure. MDS experiments characterizing the different protein conformations showed that EhADH assumes distinct structures [31]. EhSUMO silencing trophozoites showed a diminished capacity to adhere and ingest red blood cells, plausible due to a poor SUMOylation of certain proteins. However, the cytopathic effect assays evidenced that the KD-trophozoites were only poorly affected, confirming that distinct proteins are participating in adhesion, phagocytosis, and cellular destruction.

The position of EhADH and EhVps32 inside the cell, after they were hypothetically SUMOylated (deduced by the colocation images), constantly change during phagocytosis. Each protein behaved differently: colocalization of EhADH and EhSUMO significantly increased through phagocytosis, whereas EhVps32 and EhSUMO maintain a high level of colocalization since basal state. These differences could be interpreted as necessary events to carry out the distinct functions of the proteins. Our work with EhADH since many years ago [41], has evidenced its interaction with many other molecules, such as EhVps32 [14] and EhNPC1 and EhNPC2 [57] as it has been described for other ALIX family proteins [58], thus, it is possible that the protein conformation could be altered according to the target protein. Moreover, these four proteins presented putative SUMOylation sites in our in silico screening. Meanwhile, the EhVps32 movement is probably limited to the ESCRT-III complex participation. Hence, SUMOylation could enable them to move in the cell and perform their functions.

Karpiyevich and Artavanis-Tsakonas in 2020 [44] postulated that in addition to fulfiling the conserved functions described for these modifiers, Ub1s participate in novel parasite-specific roles. The data presented here, support the Karpiyevich and ArtavanisTsakonas hypothesis [44], suggesting that proteins involved in phagocytosis of E. histolytica trophozoites suffer SUMOylation, as a requisite to carry out their tasks. In conclusion, our findings point out the importance of SUMOylation in phagocytosis. Based on these data, it is possible that in the future, inhibition of SUMOylation in E. histolytica and in other parasites could help to find novel therapeutic methods to defeat amoebiasis and other parasitic diseases. 


\section{Materials and Methods}

\subsection{Culture of Trophozoites and Epithelial Cells}

Trophozoites of E. histolytica, clone A (strain HM1: IMSS) [59], were axenically cultured in TYI-S-33 medium at $37^{\circ} \mathrm{C}$ and harvested in a logarithmic growth phase for all experiments [60].

Madin Darby canine kidney (MDCK) epithelial cells were grown in DMEM medium (Gibco) supplemented with $100 \mathrm{IU} / \mathrm{mL}$ penicillin (in vitro), $100 \mathrm{mg} / \mathrm{mL}$ streptomycin (in vitro), $10 \%$ fetal bovine serum (Gibco), and $0.08 \mathrm{U} / \mathrm{mL}$ insulin (Eli Lilly), at $37^{\circ} \mathrm{C}$ in a $95 \%$ air and $5 \% \mathrm{CO}_{2}$ atmosphere.

\subsection{SUMO Searching and Phylogenetic Analysis}

Full-length sequence of SUMO gene was identified in the E. histolytica genome, using the BLASTP algorithm (http:/ / blast.ncbi.nlm.nih.gov/ / Blast.cgi accessed on 29 April 2021) and the AmoebaDB database (www.amoebadb.org accessed on 29 April 2021). Additionally, SUMO proteins of G. lamblia (accession number GL50803_7760), H. sapiens (accession number NP_001005781), and S. cerevisiae (accession number NP_010798.1) were also explored. The EhSUMO sequence was analyzed and 5' and 3' end primers were designed, to amplify the full-length gene. The putative amino acid sequence of EhSUMO (EHI_170060) was aligned with its orthologous by ClustalW and data were submitted to phylogenetic analysis by UPGMA, using MEGA 5.05 software. The bootstrapping was performed in 1000 replicates.

\subsection{Secondary and Tertiary Structure of EhSUMO}

By in silico analysis, the ubiquitin-2 Rad60 domain, characteristic of SUMO proteins, was located and aligned in the putative EhSUMO amino acid sequence and compared with SUMO orthologous, to design the secondary structure of the protein. The predicted 3D structure of EhSUMO was obtained using the crystal of $H$. sapiens (PDB:1A5R) and S. cerevisiae (PDB:1L2N). To obtained the predicted 3D structure of G. lamblia SUMO, we submitted the protein sequence V6TGL retrieved from UniProtKB, to the I-TASSER server and the higher $\mathrm{C}$-score was selected. The structural alignment of proteins was visualized with VMD [61].

\subsection{Molecular Dynamics Simulations (MDS)}

To predict the interaction between EhSUMO and EhVps32 or EhADH proteins, we performed molecular dynamics simulations (MDS) of the predicted 3D model of EhSUMO and EhVps32 and we took the published data for the 3D model of EhADH [31]. The 3D model of EhSUMO and EhVPS32 was obtained from their amino acid sequences using ID C4M1C8 and C4M1A5, respectively (uniprot.https/ / www.uniprot.org accessed on 29 April 2021), and the I-TASSER server (https:/ / zhanglab.ccmb.med.umich.edu/ITASSER accessed on 29 April 2021). The crystallographic structures that I-TASSER used to obtain the 3D EhSUMO model were: 5GJL solution structure of Plasmodium falciparum, IWZ0 solution structure of human SUMO-2 (SMT3B), a ubiquitin-like protein 5XQM structure of SMO1, SUMO homolog of Caenorhabditis elegans, and 2K8H solution structure of SUMO from Trypanosoma brucei. Those used for the EhVps32 model were: 5FD7 and 5FD9 crystal structures of ESCRT-III Snf7 core domain (conformation A and B, respectively) from Saccharomyces cerevisiae, 5NNV structure of a Bacillus subtilis Sms coiled-coil middle fragment, 2GD5 structural basils for budding by ESCRT-III factor ChMP3 from $\mathrm{H}$. sapiens and $5 \mathrm{NL}$ crystal structure of the two spectrin repeated domains from E. histolytica.

MDS were carried out using the NAMD 2.8 software [62], through GPU-CUDA with video card graphics NVIDIA Tesla C2070/Tesla C2075. The force fields CHARMM22 and CHARMM27 [63] were used to create the topologies for protein and lipids, respectively. The TIP3 model was employed for water molecules. The system was solvated by the psfgen software in the VMD program [61]. By this software, the NAMD program added water molecules and sodium ions to neutralize the system: one sodium ion was added to 
EhSUMO with 29,329 water molecules, and 14 sodium ions with 8719 water molecules to neutralize the system for EhVps32. Both systems were minimized for 1000 steps followed by equilibration, under constant temperature and pressure (NPT) conditions for one ns with protein and lipid atoms restrained. Afterward, 200-ns-long MDS was run, considering EhSUMO and EhVPS32 proteins as soluble, without position restraints under periodic boundary conditions, and using an NPT ensemble at $310 \mathrm{~K}$. Particle mesh Ewald technique was calculated for the electrostatic interactions method [64]. Nine A cut-off was used for the van der Waals interactions. The time step was set to $2.0 \mathrm{fs}$, and the coordinates were saved for analyses every one ps; 200 ns of MDS was carried out for both proteins, then, protein-protein docking calculations were performed using different conformers through 200 ns of MDS. Simulations were performed in the Laboratory of Molecular Modelling and Bioinformatics of the Facultad de Ciencias Químico Biológicas de la Universidad Autónoma de Sinaloa and the Hybrid Cluster Xiuhcoatl (http: / / clusterhibrido.cinvestav.mx accessed on 29 April 2021) of CINVESTAV-IPN, México.

The structural analysis from the MDS, the root mean square fluctuation (RMSF), and the radius of gyration $(\mathrm{Rg})$, as well as the snapshots used for docking analysis, were obtained and analyzed with the grcarma software [65]. Root mean square deviation (RMSD) was normalized using the SigmaPlot 12.0 software. The protein-protein predicted docking studies were calculated employing different conformers with Cluspro server [66,67]. Molecular graphics were performed in SigmaPlot 12.0 and all 3D-structures visualization was performed by VMD [61].

\subsection{Cloning of the E. histolytica SUMO Gene (EhSUMO)}

To clone EhSUMO gene, the full DNA sequence of $345 \mathrm{bp}$ was PCR-amplified, using the following specific primers: sense 5'-CCGGTACCATGTCTAATCAACCACAATATGGAATT AAATC-3' and antisense 5'-CCGGATCCTTATTTGATGTATTGAAGGTATTGAGTATTAAA AAGA-3', in a mixture containing $10 \mathrm{mM}$ dNTPs, $100 \mathrm{ng}$ of E. histolytica genomic DNA or cDNA as template, and 2.5 U of Taq DNA polymerase (Gibco). PCR assay was carried out for 35 cycles $\left(1 \mathrm{~min}\right.$ at $94{ }^{\circ} \mathrm{C}, 30 \mathrm{sec}$ at $59{ }^{\circ} \mathrm{C}$, and $40 \mathrm{sec}$ at $72^{\circ} \mathrm{C}$.) The sense oligonucleotide contains a KpnI restriction site, while the antisense oligonucleotide harbors a BamH1 restriction site. The full-length gene was cloned in pCold II DNA plasmid, which conferred a histidine tag [68]. As a positive control of the reaction, we use primers to amplify the Ehgata gene [69]. Two negative controls were included: in the first, water was used instead of template; and in the second, the DNAse was omitted in the mixture.

\subsection{Expression and Purification of Recombinant Protein, and Generation of Anti-Ehsumo Antibodies \\ Escherichia coli BLI21 (pLysS) bacteria were transformed with the pCold/EhSUMO,} containing the full open reading frame of the EhSUMO gene to produce a His-tagged EhSUMO recombinant protein (rEhSUMO). The His-rEhSUMO protein was purified with cobalt beads in an imidazole gradient and used to subcutaneously and intramuscularly inoculate Wistar rats (50 $\mathrm{mg}$ emulsified in Titer-Max Classic adjuvant, 1:1) (Sigma), to generate $\alpha$-EhSUMO polyclonal antibodies. Two more doses (50 $\mu \mathrm{g})$ were injected at 15-days intervals, and animals were bled to obtain the immune serum. Pre-immune serum was also obtained, before immunization.

\subsection{Production of the $\alpha$-EhADH18 Antibody}

The KFRQFENDIKLLCEGNIQ peptide from EhADH (495 to 512 amino acids) was synthesized together with the KLH (Keyhole Limpet Hemocyanin) tag to increase its immunogenicity (GenScript, Piscataway, NJ, USA). New Zeland rabbit (already-existing collection) was immunized with $600 \mu \mathrm{g}$ of the peptide resuspended in TiterMax®Gold adjuvant (1:1) (Sigma, St. Louis, MO, USA) and then, three more immunizations were performed at 15-day intervals, followed by bleeding to obtain the antibody named antiEhADH18. Pre-immune serum was also obtained, before immunizations. 


\subsection{Western Blot Experiments}

Trophozoites lysates $(35 \mu \mathrm{g})$, or purified rEhSUMO were electrophoresed in 15\% sodium dodecyl sulfate-polyacrylamide gels (SDS-PAGE), transferred to nitrocellulose membranes and probed with rat $\alpha$-EhSUMO (1:2000), mouse $\alpha$-EhVps32 (1:1000), rabbit $\alpha$-EhADH (1:1000) [34], rabbit $\alpha$-EhCPADH $(1: 35,000)$ [41], mouse $\alpha$-actin $(1: 3000)$ kindly donated by Dr. José Manuel Hernández (Cell Biology Department, CINVESTAV) and mouse $\alpha$-EhPCNA (1:500) antibodies [70]. Membranes were washed, incubated with $\alpha$-rat, $\alpha$-mouse, and $\alpha$-rabbit HRP-labeled secondary antibody (Sigma, 1:10,000), and revealed with ECL Prime detection reagent (GE-Healthcare, Chicago, IL, USA), according to the manufacturer's instructions.

\subsection{Laser Confocal Microscopy Assays}

Trophozoites were grown on coverslips, fixed with $4 \%$ paraformaldehyde at $37^{\circ} \mathrm{C}$ for $1 \mathrm{~h}$, permeabilized with $0.5 \%$ Triton X-100 and blocked with $10 \%$ fetal bovine serum in PBS. Then, cells were incubated at $4{ }^{\circ} \mathrm{C}$ for overnight (ON) with either $\alpha$-EhSUMO (1:100) or $\alpha$-EhVps32 (1:100) antibodies labeled with Alexa-555 or Pacific Blue kit (Molecular Probes-Thermo Fisher), respectively, or with rabbit $\alpha$-EhADH (1:100) antibodies. After extensive washing, samples were incubated for $30 \mathrm{~min}$ at $37^{\circ} \mathrm{C}$ with $\alpha$-rabbit FITC-labeled secondary antibody (1:100). Fluorescence was preserved using Vectashield antifade reagent (Vector), examined through a Carl Zeiss LMS 700 confocal microscope, in laser sections of $0.5 \mu \mathrm{m}$ and processed with ZEN 2009 Light Edition Software (Zeiss). To evaluate the colocation between proteins, fluorescence intensity was quantified from at least 30 confocal images, using the ImageJ $1.45 \mathrm{v}$ software and the JACoP plugin.

\subsection{In Vivo Virulence of E. histolytica Trophozoites}

Trophozoites were incubated at $4{ }^{\circ}$ and $37^{\circ} \mathrm{C}$ with erythrocytes (1:25 ratio) for different times for adhesion and phagocytosis assays, respectively [41]. For some experiments, ingested and adhered trophozoites were contrasted by Novikoff staining [71]. After phagocytosis experiments, samples were processed for immunofluorescence and western blot assays [59]. Three independent experiments were performed and the number of erythrocytes adhered or ingested per trophozoite was obtained from 100 trophozoites.

For cytopathic assays, trophozoites were incubated with confluent MDCK cell monolayers (1:20 ratio) for $1 \mathrm{~h}$. After this time, the parasites were removed by several washes with cold PBS, the remaining epithelial cells were fixed with $2.5 \%$ glutaraldehyde and stained with $1 \%$ methylene blue for $10 \mathrm{~min}$. The MDCK cell destruction was represented in comparison with control cells not incubated with trophozoites. Dye concentration was quantified using the ImageJ software [41].

\subsection{Immunoprecipitation Assays}

Trophozoites were lysed in the presence of $10 \mathrm{mM}$ Tris- $\mathrm{HCl}, 50-\mathrm{mM} \mathrm{NaCl}$, and proteases inhibitors, by freeze-thawing cycles and vortexing. Immunoprecipitation assays were performed using $200 \mu \mathrm{L}$ of protein G-agarose (Invitrogen, Carlsbad, CA, USA) and $\alpha$-EhSUMO antibody as described [14]. Immunoprecipitates were analyzed by western blot assays using $\alpha$-EhSUMO, $\alpha$-EhADH $\alpha$-EhVps32, and $\alpha$-actin antibodies, as described above.

\subsection{Silencing Assay}

The knock-down (KD) of EhSUMO was performed using the bacterial expression of double-stranded RNA (dsRNA) and parasite soaking experiments as described [39]. Briefly, the $345 \mathrm{bp}$ from the $5^{\prime}$-end of the EhSUMO gene were PCR-amplified using the following primers: sense $3^{\prime}$-CCGAGCTCATGTCTGACGCACAACATTCA- $5^{\prime}$ and antisense 3'-CCGGTACCTTAAAACCCACCAACTTGATTCAT-5'. Then, the amplicon was cloned into pJET1.2/blunt plasmid and subcloned into pL4440 plasmid, using the Sac1 and Kpn1 restriction sites. PCR, restriction analysis, and DNA sequencing were performed to verify 
the resulting pL4440-EhSUMO plasmid. The competent RNase III-deficient E. coli strain HT115 was transformed with the pL4440-EhSUMO. Bacteria were grown at $37^{\circ} \mathrm{C}$ in LB broth for plasmid construction or 2YT broth for dsRNA expression, in the presence of ampicillin $(100 \mathrm{mg} / \mathrm{mL})$ and tetracycline $(10 \mathrm{mg} / \mathrm{mL})$ [72]. The expression of EhSUMOdsRNA was induced with 2-mM isopropyl $\beta$-D-1-thiogalactopyranoside $\mathrm{ON}$ at $37^{\circ} \mathrm{C}$. Then, bacterial pellet was mixed with $1 \mathrm{M}$ ammonium acetate and $10 \mathrm{mM}$ EDTA, incubated with phenol:chloroform:isoamyl alcohol (25:24:1) and centrifuged. The supernatant was mixed with isopropanol, centrifuged, and the nucleic acid pellet was washed with $70 \%$ ethanol. DNase I (Invitrogen) and RNase A (Ambion, Austin, TX, USA) were added to eliminate ssRNA and dsDNA molecules. EhSUMO-dsRNA was washed again with isopropanol and ethanol, analyzed by agarose gel electrophoresis, and concentration determined by spectrophotometry. Lastly, purified EhSUMO-dsRNA $(10 \mu \mathrm{g} / \mathrm{mL})$ molecules were added to trophozoites $\left(3.0 \times 10^{4}\right)$ in TYI-S-33 complete medium, and cultures were incubated at $37^{\circ} \mathrm{C}$ for $24,48,72,96$, and $120 \mathrm{~h}$. At $24 \mathrm{~h}$ was the time when silencing of the EhSUMO protein was visualized and analyzed by western blot assays and confocal microscopy. All subsequent experiments were done at this time. Trophozoites growing under standard conditions (without dsRNA), were used as controls.

\subsection{Statistical Analysis}

Statistical analyses were performed by t-Student test, using GraphPad Prism 5.0 software. The scores showing statistically significant differences are indicated with asterisks in the graphs. The corresponding $p$ values are indicated in figure legends.

\section{Conclusions}

Phagocytosis is one of the main functions that Entamoeba histolytica trophozoites carry out during the invasion of the host. Many proteins are involved in this fascinating event, in which the plasmatic membrane undergoes multiple and speedy changes. Postraduccional modifications activate proteins in the precise time that they must get involved. SUMOylation, which consists of the non-covalent binding of SUMO protein with target molecules, is one of the main changes suffered by proteins to enable them to participate in cellular functions. SUMOylation had not been studied in E. histolytica nor phagocytosis, and our working hypothesis is that this event is deeply engaged in the ingestion of target molecules and cells. The results of this paper prove the presence of an intronless bona fide EhSUMO gene encoding for a $17 \mathrm{kDa}$ protein that is actively involved in phagocytosis. Silencing of the EhSUMO gene affected the rate of adhesion and phagocytosis and to a lesser extent the cytopathic effect and interfered with the EhADH and EhVps32 function, two proteins involved in phagocytosis, strongly supporting the importance of SUMOylation in this event.

Supplementary Materials: The following are available online at https://www.mdpi.com/article/ 10.3390/ijms22115709/s1, Table S1: Putative SUMOylation sites in published proteins involved in Entamoeba histolytica phagocytosis. The access number and sequence of proteins (already identified) that participate in Entamoeba histolytica phagocytosis were obtained from KEGG (https:/ /www. genome.jp/kegg accessed on 29 April 2021), AmoebaDB (https://amoebadb.org/amoeba/app accessed on 29 April 2021) and NCBI (https:/ /www.ncbi.nlm.nih.gov accessed on 29 April 2021) databases. Then, these proteins were analysed using the GPS-SUMO 1.0 (http:/ / sumosp.biocuckoo. org accessed on 29 April 2021) program to predict SUMOylation sites. The results displayed several hypothetical sites in the studied proteins, suggesting that this posttranslational modification could regulate their function during this virulence event.

Author Contributions: Conceptualization, E.O., M.D.-H. and R.J.-R.; methodology, M.D.-H., R.J.-R., I.S.-O., G.G.-R. and D.Z.; software, R.J.-R., S.M. and A.B.; formal analysis, M.D.-H., R.J.-R., G.G.-R., S.M. and E.O.; resources, E.O.; visualization, M.D.-H., R.J.-R., I.S.-O. and G.G.-R.; writing-original draft preparation, E.O., M.D.-H., R.J.-R. and S.M.; writing-review and editing, E.O., M.D.-H., R.J.R., S.M. and A.B.; supervision, E.O. All authors have read and agreed to the published version of the manuscript. 
Funding: The work was supported by the National Council for Science and Technology (Conacyt) Grant A1-S8380 for EO and RJR received a Conacyt Postdoctoral Fellowship.

Institutional Review Board Statement: The Centre for Research and Advanced Studies (CINVESTAV) fulfill the standard of the Mexican Official Norm (NOM-062-ZOO-1999) “Technical Specifications for the Care and Use of Laboratory Animals" based on the Guide for the Care and Use of Laboratory Animals "The Guide", 2011, NRC, USA with the Federal Register Number BOO.02.03.02.01.908, awarded by the National Health Service, Food Safety and Quality (SENASICA) belong to the Animal Health Office of the Secretary of Agriculture, Livestock, Rural Development, Fisheries and Food (SAGARPA), an organization that verifies the state compliance of such NOM in Mexico. The Institutional Animal Care and Use Committee (IACUC/ethics committee) from CINVESTAV as the regulatory office for the approval of research protocols, involving the use of laboratory animals and in fulfillment of the Mexican Official Norm, has reviewed and approved all animal experiments (Protocol Number 0505-12, CICUAL 001, approval date: 15 September 2017).

Informed Consent Statement: Not applicable.

Data Availability Statement: The data presented in this study are available in article and Supplementary Materials.

Acknowledgments: The authors want to express their gratitude to LANCAD for the supercomputer time support.

Conflicts of Interest: The authors declare no conflict of interest.

\section{References}

1. Bayer, P.; Arndt, A.; Metzger, S.; Mahajan, R.; Melchior, F.; Jaenicke, R.; Becker, J. Structure determination of the small ubiquitinrelated modifier SUMO-1. J. Mol. Biol. 1998, 280, 275-286. [CrossRef]

2. Sampson, D.A.; Wang, M.; Matunis, M.J. The Small Ubiquitin-like Modifier-1 (SUMO-1) Consensus Sequence Mediates Ubc9 Binding and Is Essential for SUMO-1 Modification. J. Biol. Chem. 2001, 276, 21664-21669. [CrossRef]

3. Kamitani, T.; Nguyen, H.P.; Kito, K.; Fukuda-Kamitani, T.; Yeh, E.T. Covalent Modification of PML by the Sentrin Family of Ubiquitin-like Proteins. J. Biol. Chem. 1998, 273, 3117-3120. [CrossRef]

4. Rangasamy, D.; Woytek, K.; Khan, S.A.; Wilson, V.G. SUMO-1 Modification of Bovine Papillomavirus E1 Protein Is Required for Intranuclear Accumulation. J. Biol. Chem. 2000, 275, 37999-38004. [CrossRef] [PubMed]

5. Hoege, C.; Pfander, B.; Moldovan, G.-L.; Pyrowolakis, G.; Jentsch, S. RAD6-dependent DNA repair is linked to modification of PCNA by ubiquitin and SUMO. Nat. Cell Biol. 2002, 419, 135-141. [CrossRef]

6. Gareau, J.R.; Lima, C.D. The SUMO pathway: Emerging mechanisms that shape specificity, conjugation and recognition. Nat. Rev. Mol. Cell Biol. 2010, 11, 861-871. [CrossRef] [PubMed]

7. Schwienhorst, I.; Johnson, E.S.; Dohmen, R.J. SUMO conjugation and deconjugation. Mol. Genet. Genom. 2000, 263, 771-786. [CrossRef] [PubMed]

8. Taylor, D.L.; Ho, J.C.Y.; Oliver, A.; Watts, F.Z. Cell-cycle-dependent localisation of Ulp1, a Schizosaccharomyces pombe Pmt3 (SUMO)-specific protease. J. Cell Sci. 2002, 115, 1113-1122. [CrossRef]

9. Giri, R.; Yeh, H.-H.; Wu, C.-H.; Liu, H.-S. SUMO-1 overexpression increases RbAp46 protein stability and suppresses cell growth Anticancer Res. 2009, 28, 3749-3756.

10. Neyret-Kahn, H.; Benhamed, M.; Ye, T.; Le Gras, S.; Cossec, J.-C.; Lapaquette, P.; Bischof, O.; Ouspenskaia, M.; Dasso, M.; Seeler, J.; et al. Sumoylation at chromatin governs coordinated repression of a transcriptional program essential for cell growth and proliferation. Genome Res. 2013, 23, 1563-1579. [CrossRef]

11. Di Genova, B.M.; Da Silva, R.C.; Da Cunha, J.P.C.; Gargantini, P.R.; Mortara, R.A.; Tonelli, R.R. Protein SUMOylation is Involved in Cell-cycle Progression and Cell Morphology in Giardia lamblia. J. Eukaryot. Microbiol. 2016, 64, 491-503. [CrossRef]

12. Liao, S.; Wang, T.; Fan, K.; Tu, X. The small ubiquitin-like modifier (SUMO) is essential in cell cycle regulation in Trypanosoma brucei. Exp. Cell Res. 2010, 316, 704-715. [CrossRef]

13. Maruthi, M.; Singh, D.; Reddy, S.R.; Kumar, K.A.; Mastan, B.S.; Mishra, S. Modulation of host cell SUMOylation facilitates efficient development of Plasmodium berghei and Toxoplasma gondii. Cell. Microbiol. 2017, 19, e12723. [CrossRef] [PubMed]

14. Avalos-Padilla, Y.; Betanzos, A.; Javier-Reyna, R.; García-Rivera, G.; Chávez-Munguía, B.; Lagunes-Guillén, A.; Ortega, J.; Orozco, E. EhVps32 Is a Vacuole-Associated Protein Involved in Pinocytosis and Phagocytosis of Entamoeaba histolytica. PLOS Pathog. 2015, 11, e1005079. [CrossRef]

15. Bañuelos, C.; García-Rivera, G.; López-Reyes, I.; Mendoza, L.; González-Robles, A.; Herranz, S.; Vincent, O.; Orozco, E. EhADH112 Is a Bro1 Domain-Containing Protein Involved in the Entamoeba histolytica Multivesicular Bodies Pathway. J. Biomed. Biotechnol. 2012, 2012, 1-15. [CrossRef] 
16. López-Reyes, I.; García-Rivera, G.; Bañuelos, C.; Herranz, S.; Vincent, O.; López-Camarillo, C.; Marchat, L.A.; Orozco, E. Detection of the Endosomal Sorting Complex Required for Transport in Entamoeba histolytica and Characterization of the EhVps4 Protein. J. Biomed. Biotechnol. 2010, 2010, 1-15. [CrossRef]

17. Avalos-Padilla, Y.; Knorr, R.L.; Javier-Reyna, R.; García-Rivera, G.; Lipowsky, R.; Dimova, R.; Orozco, E. The Conserved ESCRT-III Machinery Participates in the Phagocytosis of Entamoeba histolytica. Front. Cell. Infect. Microbiol. 2018, 8. [CrossRef]

18. Walsh, J.A. Problems in Recognition and Diagnosis of Amebiasis: Estimation of the Global Magnitude of Morbidity and Mortality. Clin. Infect. Dis. 1986, 8, 228-238. [CrossRef]

19. Vranych, C.V.; Merino, M.C.; Zamponi, N.; Touz, M.C.; Rópolo, A.S. SUMOylation in Giardia lamblia: A Conserved PostTranslational Modification in One of the Earliest Divergent Eukaryotes. Biomolecules 2012, 2, 312-330. [CrossRef] [PubMed]

20. Lois, L.M.; Lima, C.D.; Chua, N.-H. Small Ubiquitin-Like Modifier Modulates Abscisic Acid Signaling in Arabidopsis. Plant Cell 2003, 15, 1347-1359. [CrossRef] [PubMed]

21. Gill, G. SUMO and ubiquitin in the nucleus: Different functions, similar mechanisms? Genes Dev. 2004, 18, 2046-2059. [CrossRef] [PubMed]

22. Kirkin, V.; Dikic, I. Role of ubiquitin- and Ubl-binding proteins in cell signaling. Curr. Opin. Cell Biol. 2007, 19, 199-205. [CrossRef]

23. Lehembre, F.; Badenhorst, P.; Müller, S.; Travers, A.; Schweisguth, F.; Dejean, A. Covalent Modification of the Transcriptional Repressor Tramtrack by the Ubiquitin-Related Protein Smt3 in Drosophila Flies. Mol. Cell. Biol. 2000, 20, 1072-1082. [CrossRef]

24. Huang, H.-W.; Tsoi, S.C.-M.; Sun, Y.H.; Li, S.S.-L. Identification and characterization of the SMT3 cDNA and gene encoding ubiquitin-like protein from Drosophila melanogaster. IUBMB Life 1998, 46, 775-785. [CrossRef]

25. Jones, D.; Crowe, E.; Stevens, T.A.; Candido, E.P.M. Functional and phylogenetic analysis of the ubiquitylation system in Caenorhabditis elegans: Ubiquitin-conjugating enzymes, ubiquitin-activating enzymes, and ubiquitin-like proteins. Genome Biol. 2001, 3, 1-15. [CrossRef] [PubMed]

26. Kurepa, J.; Walker, J.M.; Smalle, J.; Gosink, M.M.; Davis, S.J.; Durham, T.L.; Sung, D.-Y.; Vierstra, R.D. The Small Ubiquitin-like Modifier (SUMO) Protein Modification System in Arabidopsis. J. Biol. Chem. 2003, 278, 6862-6872. [CrossRef] [PubMed]

27. Braun, L.; Cannella, D.; Pinheiro, A.M.; Kieffer, S.; Belrhali, H.; Garin, J.; Hakimi, M.-A. The small ubiquitin-like modifier (SUMO)-conjugating system of Toxoplasma gondii. Int. J. Parasitol. 2009, 39, 81-90. [CrossRef]

28. Dohmen, R.J. SUMO protein modification. Biochim. Biophys. Acta Bioenerg. 2004, 1695, 113-131. [CrossRef]

29. Zhao, J. Sumoylation regulates diverse biological processes. Cell. Mol. Life Sci. 2007, 64, 3017-3033. [CrossRef]

30. Sheng, Z.; Wang, X.; Ma, Y.; Zhang, D.; Yang, Y.; Zhang, P.; Zhu, H.; Xu, N.; Liang, S. MS-based strategies for identification of protein SUMOylation modification. Electrophoresis 2019, 40, 2877-2887. [CrossRef]

31. Valdez, M.S.; Orozco, E.; Correa-Basurto, J.; Bello, M.; Chávez-Munguía, B.; Betanzos, A. Heterodimerization of the Entamoeba histolytica EhCPADH virulence complex through molecular dynamics and protein-protein docking. J. Biomol. Struct. Dyn. 2016, 35, 486-503. [CrossRef]

32. Johnson, E.S. Protein Modification by SUMO. Annu. Rev. Biochem. 2004, 73, 355-382. [CrossRef]

33. Park-Sarge, O.K.; Sarge, K.D. Detection of sumoylated proteins. Methods Mol. Biol. 2008, 464, 255-265. [CrossRef]

34. Arroyo, R.; Orozco, E. Localization and identification of Entamoeba histolytica ahesin. Mol. Biochem Parasitol. 1987, $23,151-158$. [CrossRef]

35. Zhao, Q.; Xie, Y.; Zheng, Y.; Jiang, S.; Liu, W.; Mu, W.; Liu, Z.; Zhao, Y.; Xue, Y.; Ren, J. GPS-SUMO: A tool for the prediction of sumoylation sites and SUMO-interaction motifs. Nucleic Acids Res. 2014, 42, W325-W330. [CrossRef]

36. Eberhart, R.; Kennedy, J. A new Optimizer Using Particle Swarm Theory. In Proceedings of the MHS'95 Proceedings of the Sixth International Symposium on Micro Machine and Human Science, Nagoya, Japan, 4-6 October 1995; pp. 39-43. [CrossRef]

37. Perry, J.J.P.; Tainer, J.A.; Boddy, M.N. A SIM-ultaneous role for SUMO and ubiquitin. Trends Biochem. Sci. 2008, 33, 201-208. [CrossRef] [PubMed]

38. Javier-Reyna, R.; Montaño, S.; García-Rivera, G.; Rodríguez, M.A.; González-Robles, A.; Orozco, E. EhRabB mobilises the EhCPADH complex through the actin cytoskeleton during phagocytosis of Entamoeba histolytica. Cell. Microbiol. 2019, 21 , e13071. [CrossRef] [PubMed]

39. Solís, C.F.; Santi-Rocca, J.; Perdomo, R.; Weber, C.; Guillén, N. Use of Bacterially Expressed dsRNA to Downregulate Entamoeba histolytica Gene Expression. PLoS ONE 2009, 4, e8424. [CrossRef]

40. Geiss-Friedlander, R.; Melchior, F. Concepts in sumoylation: A decade on. Nat. Rev. Mol. Cell Biol. 2007, 8, 947-956. [CrossRef]

41. García-Rivera, G.; Rodríguez, M.A.; Ocádiz, R.; Martínez-López, M.C.; Arroyo, R.; González-Robles, A.; Orozco, E. Entamoeba histolytica: A novel cysteine protease and an adhesin form the $112 \mathrm{kDa}$ surface protein. Mol. Microbiol. 1999, 33, 556-568. [CrossRef]

42. Orozco, E.; Marchat, L.A.; Gómez, C.; López-Camarillo, C.; Pérez, D.G. Drug Resistance Mechanisms in Entamoeba histolytica, Giardia lamblia, Trichomonas vaginalis, and Opportunistic Anaerobic Protozoa. Antimicrob. Drug Resist. 2009, 549-559. [CrossRef]

43. Van Der Veen, A.G.; Ploegh, H.L. Ubiquitin-Like Proteins. Annu. Rev. Biochem. 2012, 81, 323-357. [CrossRef]

44. Karpiyevich, M.; Artavanis-Tsakonas, K. Ubiquitin-Like Modifiers: Emerging Regulators of Protozoan Parasites. Biomolecules 2020, 10, 1403. [CrossRef] [PubMed]

45. Sylvestersen, K.B.; Young, C.; Nielsen, M.L. Advances in characterizing ubiquitylation sites by mass spectrometry. Curr. Opin. Chem. Biol. 2013, 17, 49-58. [CrossRef] [PubMed] 
46. Sundaramoorthy, V.; Green, D.; Locke, K.; O’Brien, C.M.; Dearnley, M.; Bingham, J. Novel role of SARM1 mediated axonal degeneration in the pathogenesis of rabies. PLoS Pathog. 2020, 16, e1008343. [CrossRef]

47. Gill, G. Something about SUMO inhibits transcription. Curr. Opin. Genet. Dev. 2005, 15, 536-541. [CrossRef]

48. Verger, A.; Perdomo, J.; Crossley, M. Modification with SUMO. EMBO Rep. 2003, 4, 137-142. [CrossRef] [PubMed]

49. Wang, Z.; Zhu, W.-G.; Xu, X. Ubiquitin-like modifications in the DNA damage response. Mutat. Res. Mol. Mech. Mutagen. 2017, 803-805, 56-75. [CrossRef]

50. Enserink, J.M. Regulation of Cellular Processes by SUMO: Understudied Topics. In SUMO Regulation of Cellular Processes (Advances in Experimental Medicine and Biology, 963), 2nd ed.; Wilson, V., Ed.; Springer International Publishing: Cham, Switzerland, 2017; pp. 89-97. [CrossRef]

51. Rothenbusch, U.; Sawatzki, M.; Chang, Y.; Caesar, S.; Schlenstedt, G. Sumoylation regulates Kap114-mediated nuclear transport. EMBO J. 2012, 31, 2461-2472. [CrossRef]

52. Arya, S.; Sharma, G.; Gupta, P.; Tiwari, S. In silico analysis of ubiquitin/ubiquitin-like modifiers and their conjugating enzymes in Entamoeba species. Parasitol. Res. 2012, 111, 37-51. [CrossRef]

53. Kumari, R.; Gupta, P.; Tiwari, S. Ubc7/Ube2g2 ortholog in Entamoeba histolytica: Connection with the plasma membrane and phagocytosis. Parasitol. Res. 2018, 117, 1599-1611. [CrossRef]

54. Meulmeester, E.; Kunze, M.; Hsiao, H.H.; Urlaub, H.; Melchior, F. Mechanism and Consequences for Paralog-Specific Sumoylation of Ubiquitin-Specific Protease 25. Mol. Cell 2008, 30, 610-619. [CrossRef]

55. Shang, Q.; Xu, C.; Zhang, J.; Zhang, X.; Tu, X. Solution structure of SUMO from Trypanosoma brucei and its interaction with Ubc9. Proteins Struct. Funct. Bioinform. 2009, 76, 266-269. [CrossRef]

56. Kerscher, O.; Felberbaum, R.; Hochstrasser, M. Modification of Proteins by Ubiquitin and Ubiquitin-Like Proteins. Annu. Rev. Cell Dev. Biol. 2006, 22, 159-180. [CrossRef]

57. Bolaños, J.; Betanzos, A.; Javier-Reyna, R.; Rivera, G.G.; Huerta, M.; Pais-Morales, J.; Gonzalez-Robles, A.; Rodríguez, M.A.; Schnoor, M.; Orozco, E. EhNPC1 and EhNPC2 Proteins Participate in Trafficking of Exogenous Cholesterol in Entamoeba histolytica Trophozoites: Relevance for Phagocytosis. PLoS Pathog. 2016, 12, e1006089. [CrossRef]

58. McCullough, J.; Fisher, R.D.; Whitby, F.G.; Sundquist, W.I.; Hill, C.P. ALIX-CHMP4 interactions in the human ESCRT pathway. Proc. Natl. Acad. Sci. USA 2008, 105, 7687-7691. [CrossRef]

59. Orozco, E.; Suárez, M.E.; Sánchez, T. Differences in adhesion, phagocytosis and virulence of clones from Entamoeba histolytica, strain HM1: IMSS. Int. J. Parasitol. 1985, 15, 655-660. [CrossRef]

60. Diamond, L.S.; Harlow, D.R.; Cunnick, C.C. A new medium for the axenic cultivation of Entamoeba histolytica and other Entamoeba. Trans. R. Soc. Trop. Med. Hyg. 1978, 72, 431-432. [CrossRef]

61. Humphrey, W.; Dalke, A.; Schulten, K. William Humphrey, “Visual Molecular Dynamics.Pdf”. J. Mol. Graph. 1996, 4, 33-38. [CrossRef]

62. Kale, L.V.; Bhatele, A. Scalable Molecular Dynamics with NAMD. Parallel Sci. Eng. Appl. 2016, 26, 91-107. [CrossRef]

63. MacKerell, A.D.; Bashford, D.; Bellott, M.; Dunbrack, R.L.; Evanseck, J.D.; Field, M.J.; Fischer, S.; Gao, J.; Guo, H.; Ha, S.; et al. All-Atom Empirical Potential for Molecular Modeling and Dynamics Studies of Proteinst. J. Phys. Chem. B 1998, 102, 3586-3616. [CrossRef]

64. Batcho, P.F.; Case, D.A.; Schlick, T. Optimized particle-mesh Ewald/multiple-time step integration for molecular dynamics simulations. J. Chem. Phys. 2001, 115, 4003-4018. [CrossRef]

65. Koukos, P.I.; Glykos, N.M. Grcarma: A fully automated task-oriented interface for the analysis of molecular dynamics trajectories. J. Comput. Chem. 2013, 34, 2310-2312. [CrossRef]

66. Comeau, S.R.; Gatchell, D.W.; Vajda, S.; Camacho, C.J. ClusPro: An automated docking and discrimination method for the prediction of protein complexes. Bioinformatics 2004, 20, 45-50. [CrossRef]

67. Kozakov, D.; Beglov, D.; Bohnuud, T.; Mottarella, S.E.; Xia, B.; Hall, D.R.; Vajda, S. How Good is Automated Protein Docking? Proteins Struct. Funct. Bioinform. 2013, 81, 2159-2166. [CrossRef] [PubMed]

68. Luis, B.G.; Pastor-Palacios, G.; Rodriguez-Rocha, R.; Azuara-Liceaga, E. Cloning and initial characterization of a family A DNA polymerase from Entamoeba histolytica: A putative mitochondrial DNA Polymerase. FASEB J. 2007, 21, A1039.

69. Huerta, M.; Reyes, L.; García-Rivera, G.; Bañuelos, C.; Betanzos, A.; Díaz-Hernández, M.; Galindo, A.; Bolaños, J.; Cárdenas, H.; Azuara-Liceaga, E.; et al. A noncanonical GATA transcription factor of Entamoeba histolytica modulates genes involved in phagocytosis. Mol. Microbiol. 2020, 114, 1019-1037. [CrossRef] [PubMed]

70. Trasviña-Arenas, C.H.; Cardona-Felix, C.S.; Azuara-Liceaga, E.; Díaz-Quezada, C.; Brieba, L.G. Proliferating cell nuclear antigen restores the enzymatic activity of a DNA ligase I deficient in DNA binding. FEBS Open Biol. 2017, 7, 659-674. [CrossRef] [PubMed]

71. Novikoff, A.B.; Novikoff, P.M.; Davis, C.; Quintana, N. Studies on microperoxisomes II. A cytochemical method for light and electron microscopy. J. Histochem. Cytochem. 1972, 20, 1006-1023. [CrossRef]

72. Takiff, H.E.; Chen, S.-M.; Court, D.L. Genetic analysis of the rnc operon of Escherichia coli. J. Bacteriol. 1989, 171, 2581-2590. [CrossRef] 